\title{
Cyclin D1 integrates G9a-mediated histone methylation
}

\author{
Zhiping $\mathrm{Li}^{1} \cdot$ Xuanmao Jiao ${ }^{1} \cdot$ Gabriele Di Sante ${ }^{1} \cdot$ Adam Ertel $^{2} \cdot$ Mathew C. Casimiro ${ }^{1} \cdot$ Min Wang $^{1} \cdot$ Sanjay Katiyar $^{1} \cdot$

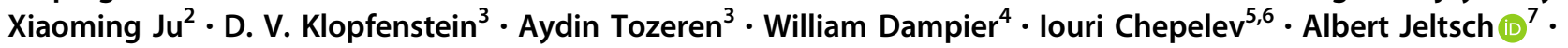 \\ Richard G. Pestell ${ }^{1,8}$
}

Received: 6 March 2018 / Revised: 3 December 2018 / Accepted: 8 January 2019 / Published online: 4 February 2019

(c) The Author(s) 2019. This article is published with open access

\begin{abstract}
Lysine methylation of histones and non-histone substrates by the SET domain containing protein lysine methyltransferase (KMT) G9a/EHMT2 governs transcription contributing to apoptosis, aberrant cell growth, and pluripotency. The positioning of chromosomes within the nuclear three-dimensional space involves interactions between nuclear lamina (NL) and the laminaassociated domains (LAD). Contact of individual LADs with the NL are dependent upon H3K9me2 introduced by G9a. The mechanisms governing the recruitment of G9a to distinct subcellular sites, into chromatin or to LAD, is not known. The cyclin D1 gene product encodes the regulatory subunit of the holoenzyme that phosphorylates pRB and NRF1 thereby governing cellcycle progression and mitochondrial metabolism. Herein, we show that cyclin D1 enhanced H3K9 dimethylation though direct association with G9a. Endogenous cyclin D1 was required for the recruitment of G9a to target genes in chromatin, for G9ainduced $\mathrm{H} 3 \mathrm{~K} 9 \mathrm{me} 2$ of histones, and for NL-LAD interaction. The finding that cyclin D1 is required for recruitment of G9a to target genes in chromatin and for H3K9 dimethylation, identifies a novel mechanism coordinating protein methylation.
\end{abstract}

These authors contributed equally: Zhiping Li, Xuanmao Jiao, Gabriele Di Sante

Supplementary information The online version of this article (https:// doi.org/10.1038/s41388-019-0723-8) contains supplementary material, which is available to authorized users.

Richard G. Pestell

richard.pestell@bblumberg.org

1 Pennsylvania Cancer and Regenerative Medicine Research Center, Baruch S. Blumberg Institute, Pennsylvania Biotechnology Center, 3805 Old Easton Rd., Doylestown, PA 18902, USA

2 Department of Cancer Biology, Thomas Jefferson University, 233 South 10th Street, Philadelphia, PA 19107, USA

3 Center for Integrated Bioinformatics, School of Biomedical Engineering, Drexel University, Philadelphia, PA 19104, USA

4 Department of Microbiology \& Immunology, Drexel University College of Medicine, Philadelphia, PA 19104, USA

5 Center for Autoimmune Genomics and Etiology, Cincinnati Children's Hospital Medical Center, Cincinnati, OH 45229, USA

6 Department of Pediatrics, University of Cincinnati College of Medicine, Cincinnati, OH 45267, USA

7 Department of Biochemistry, Institute of Biochemistry and Technical Biochemistry, University of Stuttgart, Allmandring 31, D-70569 Stuttgart, Germany

8 Lee Kong Chian School of Medicine, Nanyang Technological University, Singapore 637551, Singapore

\section{Introduction}

Histone methylation is dynamically regulated by histone methyltransferases (HKMTs) and histone lysine demethylases [1]. Both histone and non-histone substrates have been reported for HKMTs therefore these enzymes are referred to as lysine methyltransferases (KMTs) and lysine demethylases. The key KMTs include G9a/KMT1C, which methylates histone $\mathrm{H} 1$ and $\mathrm{H} 3$ (K9 and K27) in vitro. The Su(var) 3-9-Enhancer of zeste-Trithorax (SET) domain of Suv39h1/ KMT1a encodes the catalytic domain, which governs lysine methylation [2]. Both Suv39h1 and G9a catalyze mono-, di-, and tri-methylation reactions on $\mathrm{H} 3 \mathrm{~K} 9$ [3, 4]. In mouse and human, the G9a/GLP enzymatic complex di-methylates H3K9. G9a is therein essential for both the stability of the complex and the catalytic function [5]. G9a associates with heterochromatin protein 1 (HP1) to regulate chromatin binding and association with methylated histones [6]. Distinct domains of G9a, including the Cys-rich region (CYS), the ankyrin repeat (ANK), and the SET domain, facilitate interactions with either methylated histones or associated proteins. The recruitment of HP1 $\alpha$ and HP1 $\beta$ to pericentromeric heterochromatin is dependent upon $\mathrm{H} 3 \mathrm{~K} 9$ methylation by Suv39h. HP1 $\alpha$ then binds to $\mathrm{H} 3 \mathrm{~K} 9 \mathrm{me} 2$ and H3K9me3. The association of G9a with HP1 to form complexes increases the automethylation of G9a [6-8]. The 
association of the multi H3K9 methyl-binding protein modules, which includes HP1 and G9a, may result in the spreading of $\mathrm{H} 3 \mathrm{~K} 9 \mathrm{me} 2$ marks [9]. The non-histone substrates of G9a include p53, Wiz, CDYL1, ACINUS, and Reptin [10-13].

The nuclear lamina (NL) interacts with genomic regions referred to as lamina-associated domains (LADs) and G9a plays a critical role in NL-associated large chromatin domain interactions. Recent evidence suggests the contact of NL with LADs is linked to H3K9 dimethylation introduced by G9a [14]. G9a thereby contributes to architectural changes of chromosomes and in turn participates in gene regulation. Approximately $40 \%$ of the mammalian genome are covered by LADs. LAD interactions with NL may provide structural impediments that positioning the chromosomes. The mechanisms governing LAD-NL association is contingent upon long $(\mathrm{GA})_{n}$ repeats [15]. Furthermore, $\mathrm{H} 3 \mathrm{~K} 9$ methylation contributes to NL anchoring to genomic loci [16]. The mechanisms coordinating the interactions between LAD and NL remain to be determined. Because a variety of diseases have been linked to dysfunctional interaction of NL-associated proteins and chromatin components [17], it remains important to discern the mechanism governing these interactions.

Recently, a new approach was developed for studying NL-LAD interactions using an epigenetic tag of DNA adenine-6-methylation. DNA in contact with the NL becomes adenine methylated via an Escherichia coli DNA adenine methyltransferase and Lamin B fusion protein. Because ${ }^{\mathrm{m} 6} \mathrm{~A}$ is a stable modification, DNA in contact with the NL can be labeled and thereby visualized in living cells. Using this approach, G9a was shown to control H3K9 dimethylation, which was critical for LAD-NL interactions and thereby determined the contact of LADs with the NL [14]. G9a is known to colocalize with the replication foci during DNA synthesis, and shortly prior to incorporation into chromatin, G9a complexes deposit K9me2 marks on H3 [18, 19].

The cyclin Dl gene encodes a labile regulatory subunit of the holoenzyme that phosphorylates and inactivates the retinoblastoma (pRb) [20] and NRF1 [21] proteins thereby coordinating both the DNA synthetic phase of the cell cycle and mitochondrial biogenesis [22]. Several recent studies have implicated cyclin D1 in the regulation of gene transcription [23]. Initial studies demonstrated cyclin D1 altered both transcription factor recruitment and local chromatin acetylation in chromatin immunoprecipitation (ChIP) assays [24]. Such findings were consistent with the binding of cyclin D1 to histone acetylases and deacetylases in vitro [25-28]. Cyclin D1 was subsequently identified in a DNA chromatin-associated pool linked to the regulation of gene expression, including the repression of PPAR $\gamma$ [27, 29] and unbiased genome-wide ChIP-Seq demonstrated cyclin D1 binds to the regulatory regions of genes governing chromosomal instability [30]. Cyclin D1 is known to either activate or repress gene expression, and more than 30 transcription factors and several co-activators interacting with cyclin D1 have been characterized. The regulation of gene expression by cyclin D1 involves a helix-turn-helix (HTH) domain between aa179 and 241 [27]. The biological significance of endogenous cyclin D1 in governing gene expression in vivo was evidenced by recent studies in which cyclin D1 genetic deletion attenuated both estradiol- and androgen-dependent gene expression in the mammary gland [31] and prostate, respectively [32].

We show herein that cyclin D1 governs H3K9 dimethylation of histone substrates and determines the recruitment of G9a into chromatin at gene targets. Cyclin D1 enhanced $\mathrm{H} 3 \mathrm{~K} 9 \mathrm{me} 2$ in tissue culture and in vivo in multigenic mice. Endogenous cyclin D1 bound the predominant cellular H3K9 methyltransferase G9a. The previously defined HTH transcriptional regulatory domain of cyclin D1 was required for association with G9a. Cyclin D1 binding to G9a required the CYS domain of G9a. Cyclin D1 and G9a bound common genes in genome-wide ChIP-Seq analyses, with enrichment at the LAD borders. Using ${ }^{\mathrm{m} 6} \mathrm{~A}$-tracer, we show cyclin D1 is required for the G9a-dependent association of NL with LAD. Collectively, these studies define a novel function for cyclin D1, to associate with G9a and thereby promote $\mathrm{H} 3 \mathrm{~K} 9$ dimethylation, which in turn plays an essential role in the positioning of interphase chromosomes.

\section{Results}

\section{The cyclin D1 HTH domain is required for binding to G9a}

The HMT G9a is responsible for the majority of $\mathrm{H} 3 \mathrm{~K} 9 \mathrm{me} 2$ in cells. In order to determine whether the induction of H3K9me2 at specific chromatin elements by cyclin D1 involved association of cyclin D1 with G9a, immuneprecipitation was conducted of endogenous cyclin D1 in the human MCF-7 breast cancer cell line. Cyclin D1 immunoprecipitation (IP) co-precipitated $\mathrm{pRB}, \mathrm{Cdk} 4$, and G9a (Fig. 1a). Immunofluorescence staining suggested that cyclin D1 (green) co-localized with G9a (red) in wild-type mouse embryonic fibroblasts (MEFs) in a subset of cells (Fig. 1b, yellow dots).

In order to determine which domain of cyclin D1 binds to G9a we conducted IP-western blotting of cells transfected with expression vectors encoding GAL4-tagged cyclin D1 or mutants of cyclin D1 (Fig. 1c) and a vector encoding FLAG-tagged wild-type G9a (Fig. 1d, e). IP with an antiFLAG antibody precipitated FLAG-tagged G9a and the associated GAL4-cyclin D1 fusion protein. Point mutation 
A

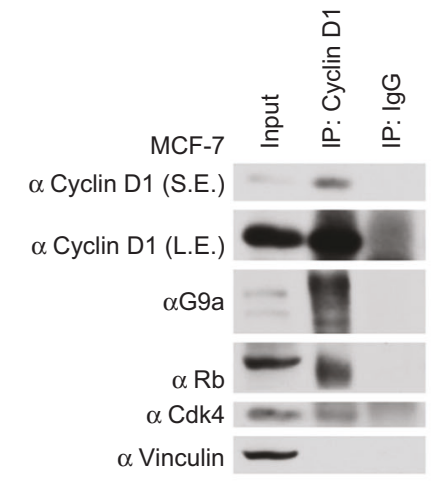

B

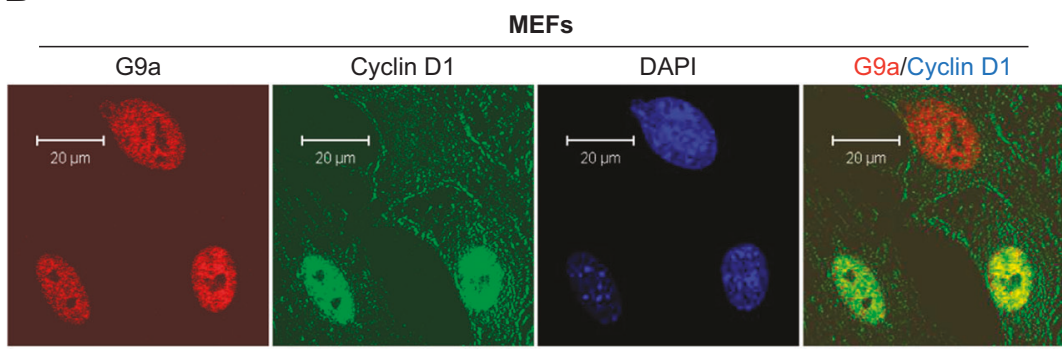

D

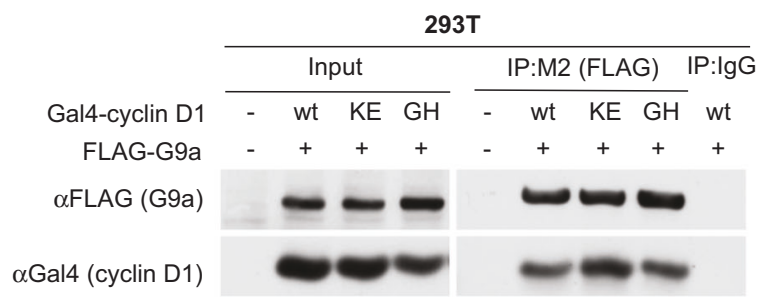

E

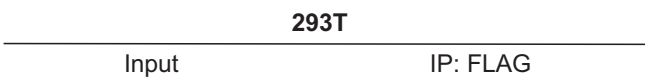

Gal4-cyclin D1 - wt N2 N4 N6 C2 C4 C6 - wt N2 N4 N6 C2 C4 C6

FLAG-G9a -+++++++-+++++++

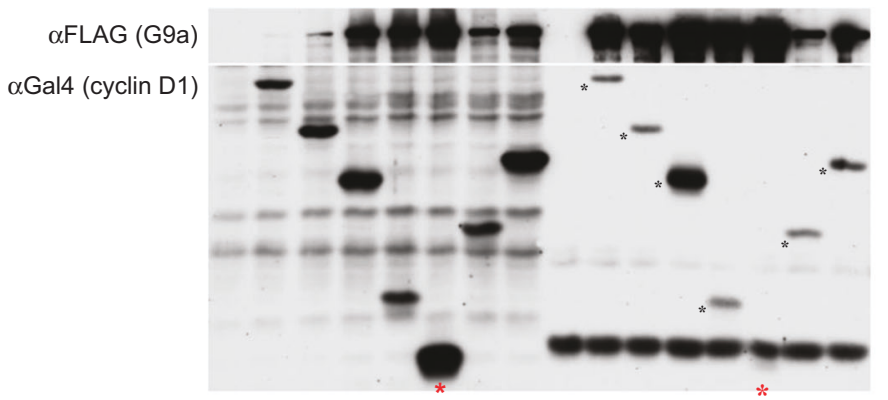

G

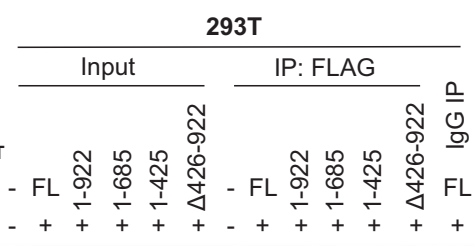

H

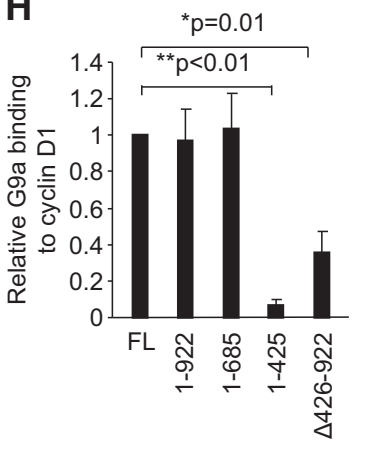

of cyclin D1 at the amino acid K112, which is known to reduce binding of $\mathrm{Cdk} 4 / \mathrm{Cdk} 6$, did not affect G9a association (Fig. 1d). As the cyclin $\mathrm{D} 1{ }^{\mathrm{KE}}$ mutant is defective in forming an active kinase function, this finding suggests G9a binding is distinct from the kinase function of cyclin D1. Similarly, the cyclin $\mathrm{D} 1^{\mathrm{GH}}$ mutant, which abrogates $\mathrm{pRb}$ binding, did not affect G9a association (Fig. 1d). We next examined the series of deletion mutants of cyclin D1. The N6 mutant was capable of binding G9a, however, the C2 mutant, which was expressed abundantly, failed to bind G9a (Fig. 1e, asterisks). The $\mathrm{C} 4$ and C6 mutants of cyclin D1 bound G9a. Because the amino terminal fragment of cyclin D1 (N6) and the C-terminal fragment (C4) were capable of binding G9a together, these studies demonstrate that the amino terminus and the amino-acid residues between 178 and 242 , corresponding to the previously described cyclin D1 transcriptional regulatory domain [27], are both required for G9a binding in IP-western blotting. 
Fig. 1 Cyclin D1 binds G9a. a Cyclin D1 immune-precipitation was conducted in MCF-7 cells, with subsequent western blotting to the proteins indicated. b Confocal microscopy of immunofluorescence for G9a (red), cyclin D1 (green), and nuclear staining with 4',6-diamidino2-phenylindole (DAPI; blue) in cyclin $\mathrm{Dl}^{+/+}$mouse embryonic fibroblasts (MEFs). Scale bar, $20 \mu \mathrm{m}$. c Schematic representation of GAL4-tagged cyclin D1 expression vectors with relative G9a binding. d Immunoprecipitation using an antibody to the FLAG-tag of G9a with sequential western blot to the GAL4 for GAL4-cyclin D1 in 293T cells co-transfected with FLAG-tagged G9a and GAL4-tagged cyclin D1 wild type, KE mutant, and GH mutant. e Immunoprecipitation using an antibody to the FLAG-tag of G9a and sequential western blotting to GAL4 for GAL4-cyclin D1 wild type and truncation mutants. Note the relative abundance of $\mathrm{C} 2$ and $\mathrm{C} 4$ in the input and lack of cyclin D1 in C2 but not in C4 by FLAG immunoprecipitation (IP)-western blot. $\mathbf{f}$ Schematic representation of FLAG-tagged G9a expression vectors with relative cyclin D1 binding. g IP-western after precipitation with anti-FLAG antibody for FLAG-tagged G9a in sequential western blotting to the GAL4 for GAL4-cyclin D1 in 293 T cells co-transfected with GAL4-tagged cyclin D1 and FLAGtagged G9a wild type and truncation mutants. h Quantitation of FLAG-tagged G9a binding to GAL4-tagged cyclin D1 in 293T cells from three independent experiments. The binding amount of FLAGtagged wild-type G9a to GAL4-tagged cyclin D1 in each experiment was set as 1 . The data are shown as mean \pm SEM. $* P=0.01 ; * * P<$ $0.01(\mathrm{n}=3)$

Quantitation of the relative association between G9a and cyclin D1 was conducted. In order to define the domains of G9a required for cyclin D1 association in IP-western blotting, a series of G9a expression vectors were deployed (Fig. 1f). The FLAG-tagged G9a expression vectors were co-expressed with cyclin D1 ${ }^{\text {WT }}$. The FLAG IP precipitated G9a and the co-associated cyclin D1 was detected by western blot (Fig. 1g). The G9a mutant 1-425 failed to bind cyclin D1 (Fig. 1g), whereas the G9a mutant 1-685 including the CYS domain was capable of binding cyclin D1 (Fig. 1g). The G9a mutant Del 426-922 without the CYS and ANK domains significantly decreased binding to cyclin D1 (Fig. 1g, h, G9a FL vs 1-425, $P<0.01$; G9a FL vs Del 426-922, $P=0.01)(n=3)$. Together, these studies demonstrate that the G9a CYS domain and the cyclin D1 HTH domain are required for co-association.

\section{Cyclin D1 maintains H3K9 dimethylation in cultured cells and in vivo}

In order to determine the role of endogenous cyclin D1 in determining cellular $\mathrm{H} 3 \mathrm{~K} 9 \mathrm{me} 2$, immunofluorescence was conducted. We examined H3K9me2, comparing the cyclin $D 1^{+/+}$, cyclin $D 1^{-/-}$MEFs, and cyclin $D 1^{-/-}$MEFs rescued with cyclin D1 or vector control (Fig. 2a, b). The relative abundance of $\mathrm{H} 3 \mathrm{~K} 9 \mathrm{me} 2$ was reduced in cyclin $\mathrm{D1} \mathrm{I}^{-1-}$ cells compared to wild-type controls. Introducing cyclin D1 into cyclin $D 1^{-1-}$ MEFs increased $\mathrm{H} 3 \mathrm{~K} 9 \mathrm{me} 2$ compared to the vector control cells (Fig. 2a, b). Introducing a point mutation of the amino acid $\mathrm{K} 112$ (KE mutant), which results in reduced binding of cdk4/cdk6 and impaired kinase activity when introduced into cyclin $D 1^{-/-}$MEFs, also enhanced H3K9me2 staining to a similar level as cyclin D1 wild type (Supplemental Fig. 1).

In order to determine whether endogenous cyclin D1 maintained $\mathrm{H} 3 \mathrm{~K} 9 \mathrm{me} 2$ in vivo, transgenic mice were used. Cyclin DI $1^{f l f l}$ mice were intercrossed with Rosa26 $6^{\text {CreERT2/CreERT2 }}$ transgenic mice, and adult mice were treated with tamoxifen to induce Cre expression and thereby cyclin Dl gene deletion (Fig. 2c). After 4 weeks of tamoxifen washout, immunohistochemical staining of H3K9me2 and cyclin D1 was conducted, demonstrating a substantial reduction in H3K9me2 upon deletion of the cyclin Dl gene (Fig. 2d, e). Cyclin D1 gene deletion was verified in these mice by genomic analysis and by immunohistochemical staining for cyclin D1 (Supplemental Fig. 2).

\section{The cyclin D1 HTH domain is required for induction of $\mathrm{H} 3 \mathrm{~K} 9 \mathrm{me} 2$}

In order to determine whether the mutant of cyclin D1 that was defective in binding to G9a was capable of inducing H3K9me2, a comparison was made between the cyclin $\mathrm{D} 1^{\mathrm{WT}}$ and the cyclin $\mathrm{D} 1^{\mathrm{C} 2}$ mutant, which is defective in binding G9a (Fig. 1c, e). Transduction of cyclin $\mathrm{Dl}^{-/-}$ MEFs with the retroviral vector encoding cyclin D1 ${ }^{\text {WT }}$ enhanced $\mathrm{H} 3 \mathrm{~K} 9 \mathrm{me} 2$, whereas transduction with the vector encoding a cyclin D1 mutant defective in binding G9a (cyclin $\mathrm{D}^{\mathrm{C} 2}$ ) failed to rescue $\mathrm{H} 3 \mathrm{~K} 9 \mathrm{me} 2$ (Fig. $3 \mathrm{a}, \mathrm{b}$ ). Western blot analysis of the cyclin D1 ${ }^{\mathrm{WT}}$ and cyclin D1 ${ }^{\mathrm{C} 2}$ mutant transduced cyclin $D 1^{-/-}$MEFs for cyclin D1 protein demonstrated the presence of the cyclin D $1^{\mathrm{WT}}$ and cyclin D1 ${ }^{\mathrm{C} 2}$ mutant protein (Fig. 3c). The abundance of H3K9me2 was induced greater than twofold by cyclin D $1^{\text {WT }}$ but not by cyclin $\mathrm{D} 1^{\mathrm{C} 2}$ mutant when normalized for protein loading abundance with Lamin B1 (Fig. 3c).

\section{H3K9 dimethylation by G9a requires cyclin D1}

Given that G9a is crucial for $\mathrm{H} 3 \mathrm{~K} 9 \mathrm{me} 2$ [5] we confirmed that deficiency of the $G 9 a$ gene in $\operatorname{MEFs}\left(G 9 a^{-/-}\right)$resulted in reduction of $\mathrm{H} 3 \mathrm{~K} 9 \mathrm{me} 2$ levels compared to the control $\left(G 9 a^{f l f l}\right)$ cells by immunofluorescence staining (Fig. 4a, b) and western blotting (Fig. 4c, d, $G 9 a^{f l f l}$ vs $G 9 a^{-/-}, P<0.01$, S.E., short exposure, L.E., long exposure). Introducing G9a into $G 9 a^{-1-}$ MEFs increased H3K9me2 by immunofluorescence compared to the vector control cells (Fig. 4a, b) and by western blot analysis (Fig. 4c, d, $G 9 a^{-1-}$ plus vector vs $G 9 a^{-1-}$ plus G9a $\left.{ }^{\mathrm{WT}}, P<0.01\right)$. Introduction of G9a short hairpin RNA (shRNA) into MCF-7 cells reduced G9a and H3K9me2 levels (Fig. 4e). In order to examine further the requirement for cyclin D1 in G9a function, we 
Fig. 2 Cyclin D1 augments H3K9me2. a Confocal microscopy of immunofluorescence for H3K9me2 (red) and nuclear staining with $4^{\prime}, 6$-diamidino-2phenylindole (DAPI; blue) in cyclin D1 wild-type and knockout mouse embryonic fibroblasts (MEFs), and cyclin $D 1^{-/-}$MEFs rescued with MSCV-cyclin D1-IRES-GFP or vector control. Images demonstrate the reduction in $\mathrm{H} 3 \mathrm{~K} 9 \mathrm{me} 2$ in cyclin $\mathrm{DI}^{-/-}$cells. Scale bar, $20 \mu \mathrm{m}$ with (b) quantitation of mean fluorescence shown as mean \pm SEM. c Schematic representation of transgenic paradigm. d

Immunohistochemical staining for $\mathrm{H} 3 \mathrm{~K} 9 \mathrm{me} 2$ in the mammary gland of transgenic mice in which the cyclin D1 gene was deleted through Cre excision in the adult mammary glands. e The quantitation of $\mathrm{H} 3 \mathrm{~K} 9 \mathrm{me} 2$ is shown as mean \pm SEM for $n=$ 10 separate mammary glands from two cyclin $D 1^{W T}$

(tamoxifen-treated cyclin $D 1^{\text {wt/wt }}$;-Rosa26 CreERT2/CreERT2 transgenic mice) and three cyclin $D 1^{-/-}$mice (tamoxifentreated cyclin $D 1^{f l f l}$;Rosa26 $6^{\text {CreERT2/CreERT2 }}$ transgenic mice)
A

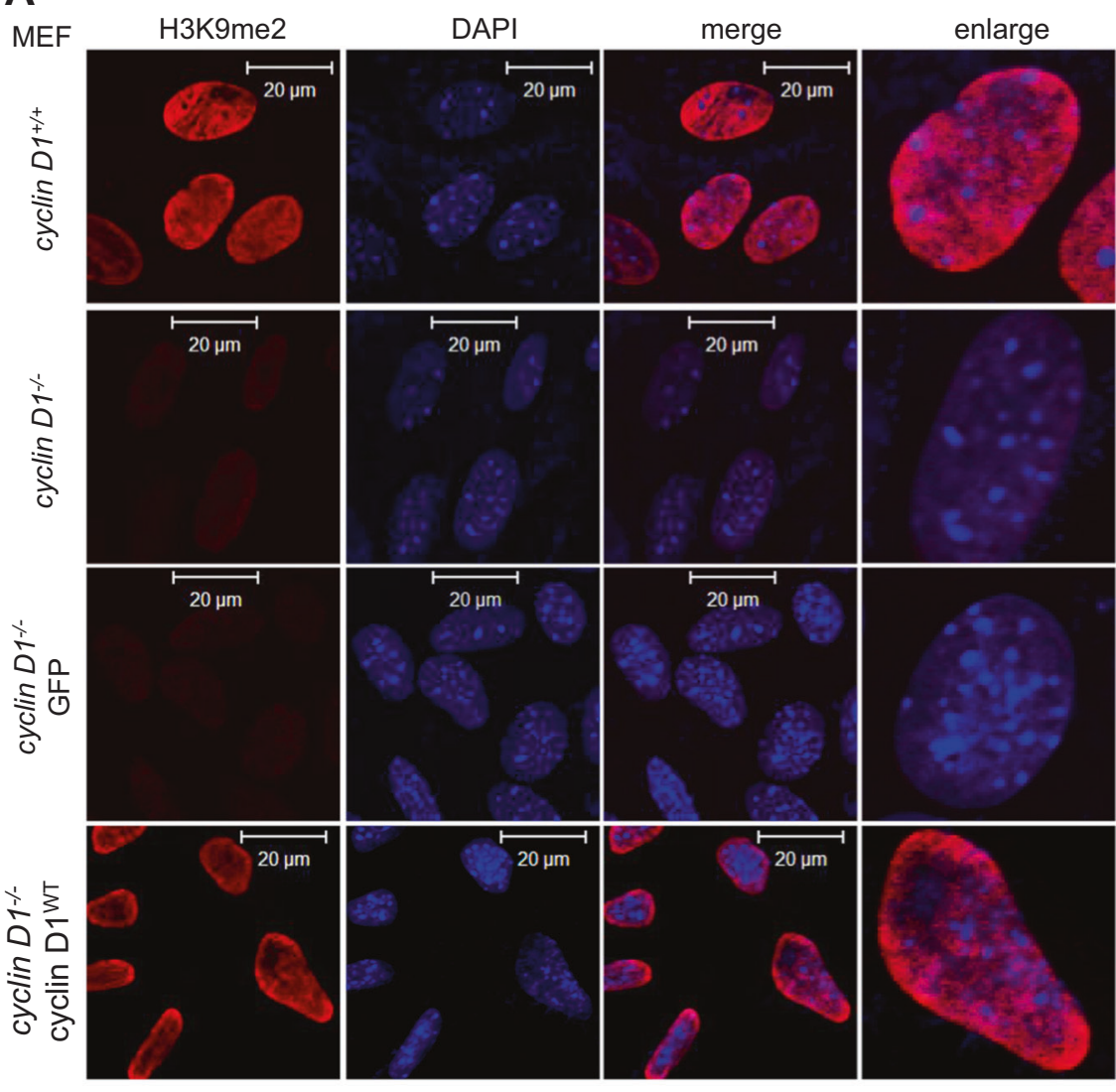

B

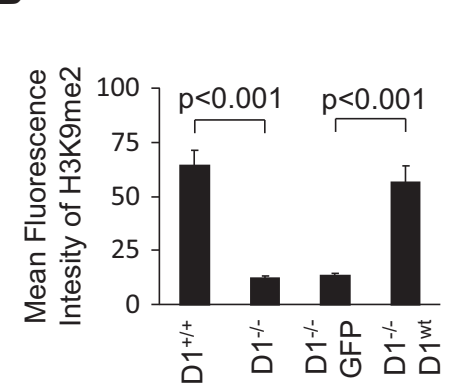

D $\mathrm{IHC}$ of $\mathrm{H} 3 \mathrm{~K} 9 \mathrm{me} 2$ in mammary gland

\section{C}

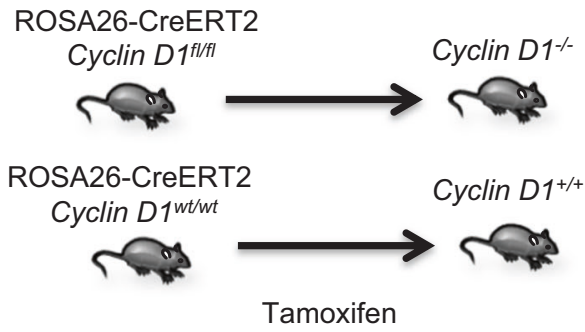

(5 Days) then 4 weeks washout

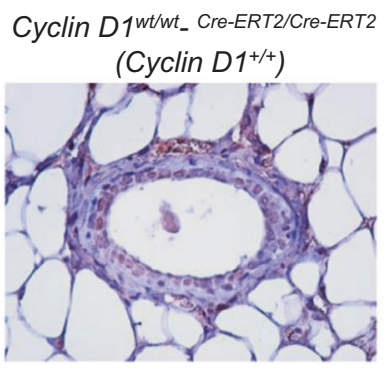

Cyclin D1fl/f;);Cre-ERT2/Cre-ERT2

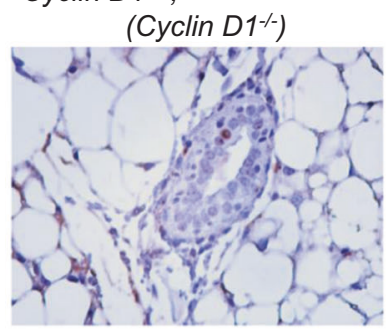

conducted cyclin D1 siRNA studies in G9a ${ }^{-/-}$or $G 9 a^{-/-}$ MEF rescued with a G9a expression vector. H3K9me2 was decreased in $\mathrm{G}^{-1-}$ cells. Addition of G9a rescued H3K9me2 (Fig. 4f, g). Cyclin D1 small interfering RNA
(siRNA) treatment reduced $\mathrm{H} 3 \mathrm{~K} 9 \mathrm{me} 2$ in $G 9 a^{-1-} \mathrm{MEF}$ rescued with a G9a expression vector. In $G 9 a^{-1-}$ plus vector cells no further decrease in $\mathrm{H} 3 \mathrm{~K} 9 \mathrm{me} 2$ was observed with cyclin D1 siRNA compared to control siRNA 
Fig. 3 The G9a-binding defective mutant of cyclin D1 fails to augment $\mathrm{H} 3 \mathrm{~K} 9 \mathrm{me} 2$. a Confocal microscopy of immunofluorescence for H3K9me2 (red) and nuclear staining with $4^{\prime}, 6$-diamidino-2phenylindole (DAPI; blue) in cyclin D1 wild-type and knockout mouse embryonic fibroblasts (MEFs), and cyclin $D 1^{-/-}$MEFs rescued with MSCV-cyclin D1 ${ }^{\text {WT }}$-IRES-GFP, MSCV-cyclin D1 ${ }^{\mathrm{C} 2}$-IRES-GFP, or vector control. Images demonstrate the reduction in $\mathrm{H} 3 \mathrm{~K} 9 \mathrm{me} 2$ in cyclin $\mathrm{DI}^{-/-}$cells and rescue with cyclin $\mathrm{D} 1^{\mathrm{WT}}$. Scale bar, $40 \mu \mathrm{m}$ with (b) quantitation of mean fluorescence shown as mean \pm SEM. c Western blot of cyclin $D 1^{-/-}$MEFs rescued with MSCV-cyclin D1 ${ }^{\mathrm{WT}}$-IRES-GFP, MSCV-cyclin D1 ${ }^{\mathrm{C} 2}$-IRES-GFP, or vector control, with antibodies as indicated
A

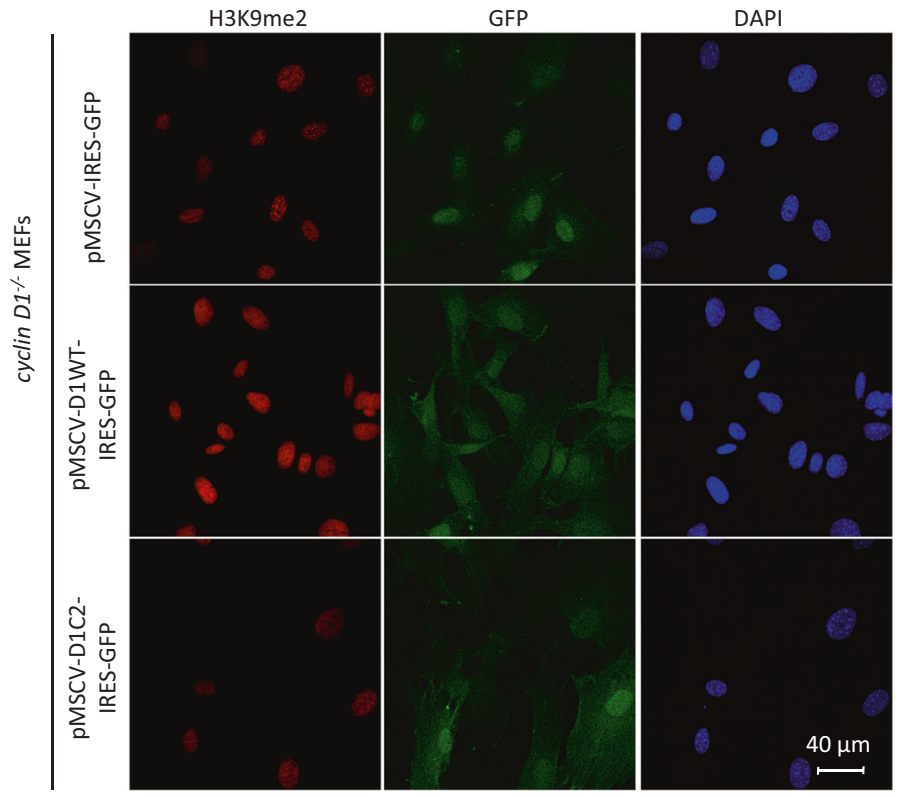

B

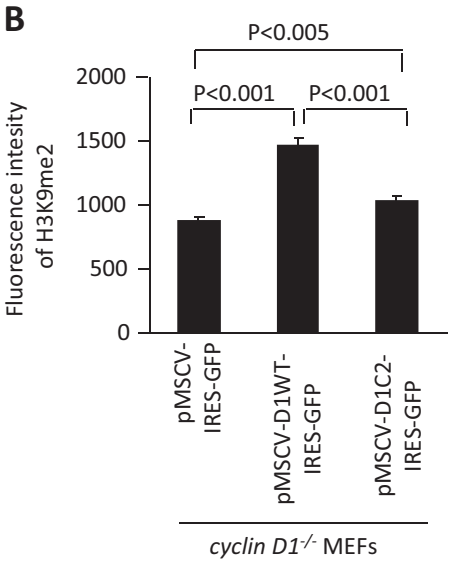

C

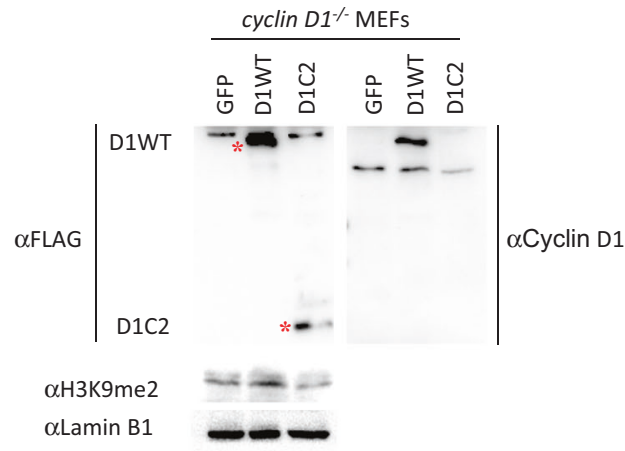

treatment (Fig. 4f, g). Thus, endogenous cyclin D1 is required for the ability of $\mathrm{G} 9 \mathrm{a}$ to introduce $\mathrm{H} 3 \mathrm{~K} 9 \mathrm{me} 2$.

\section{Cyclin D1 and G9a binding by ChIP-Seq overlap common gene regions}

We next examined occupancy of G9a and cyclin D1 in the genome by comparing ChIP-Seq [30, 33]. G9a binding and cyclin D1 binding, aligned with chromosomal location demonstrated G9a and cyclin D1 were not recruited to the X and $\mathrm{Y}$ chromosomes (Supplemental Fig. 3). Sets of genes bound by G9a in mouse embryonic stem cells (mESCs) and cyclin D1 in MEFs were obtained from published ChIP-Seq data $[30,33]$. A total of 16,173 G9a-bound genes (GEO database (accession number: GSM1215219)) and 2840 cyclin D1-bound genes were identified (Fig. 5a). Although the data sets were derived from different cell types, 744 genes were identified that were overlapping for both cyclin
D1 and G9a binding (Fig. 5a). Thus, 744/16,173 G9abinding sites are coincident for cyclin D1 (4.6\%) and 744/ 2840 of the cyclin D1-binding sites are coincident for G9a binding $(26.2 \%, P<0.01)$.

The Gene Ontology (GO) functional terms of the genes that bound both cyclin D1 and G9a in ChIP were enriched for genes involved in cellular functions including regulation of cell growth, oncogenesis, apoptosis, and neuronal function (Fig. 5b). From within the overlapping cyclin D1/G9a ChIP-Seq group several genes were chosen for further analysis based on their known role in apoptosis and cellular proliferation (Mdm4, Pttgl, and $c-M y c)$ (Fig. $5 \mathrm{c}-\mathrm{k})$. Neuronal migration and function has been shown to involve cyclin D1 [34, 35] and G9a [36], therefore seven genes were selected from the literature as shown to be linked to neurogenesis through altered expression in mouse models (Cacna2d4, Dlgap3, Glral, Scn2al, Kcne2, Stx3, and Sncb (Supplemental Figs. 4 and 5)). For 
A

G9a $a^{f / f t}$

$G 9 a^{-1-}$

G9a-/ vector

G9a $a^{-/ G 9 a}$
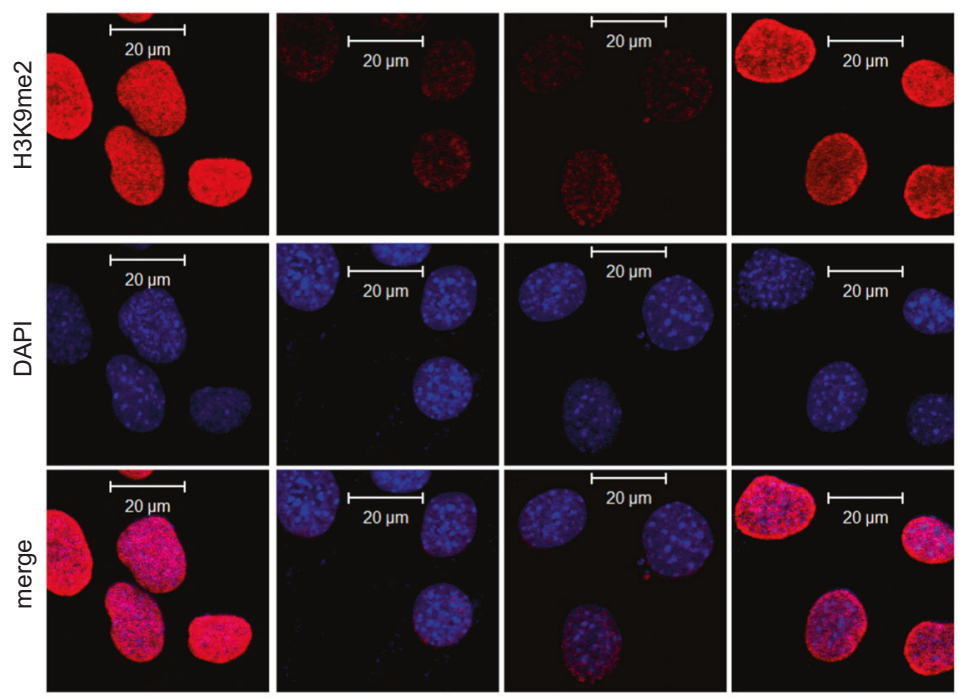

B
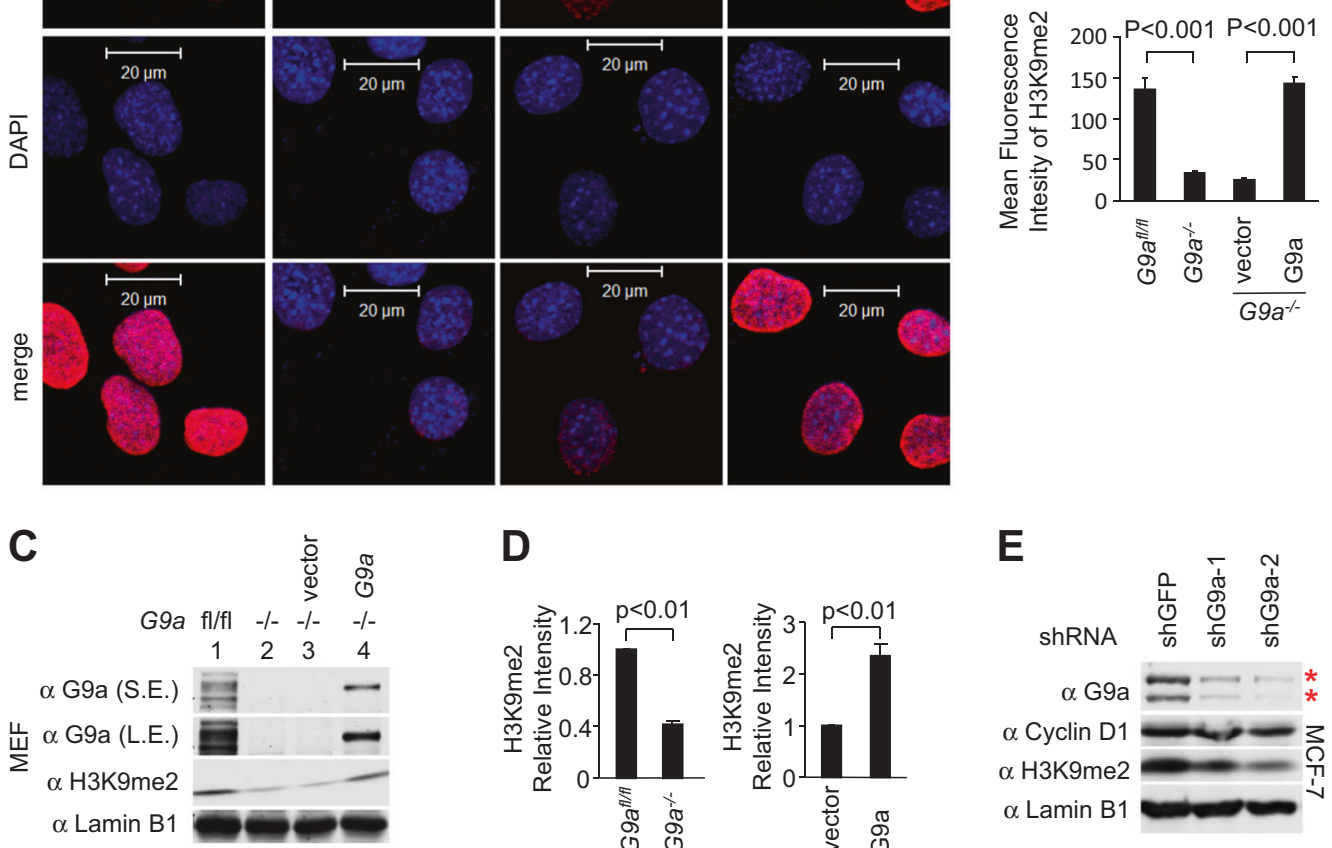

D

E
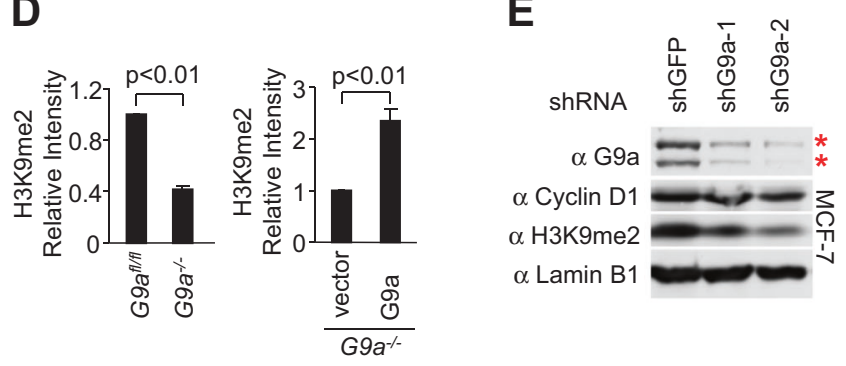

$\mathbf{F}$

G9a $a^{-/-}$MEFs

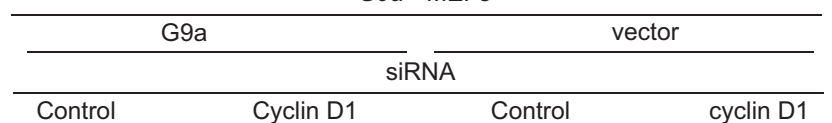
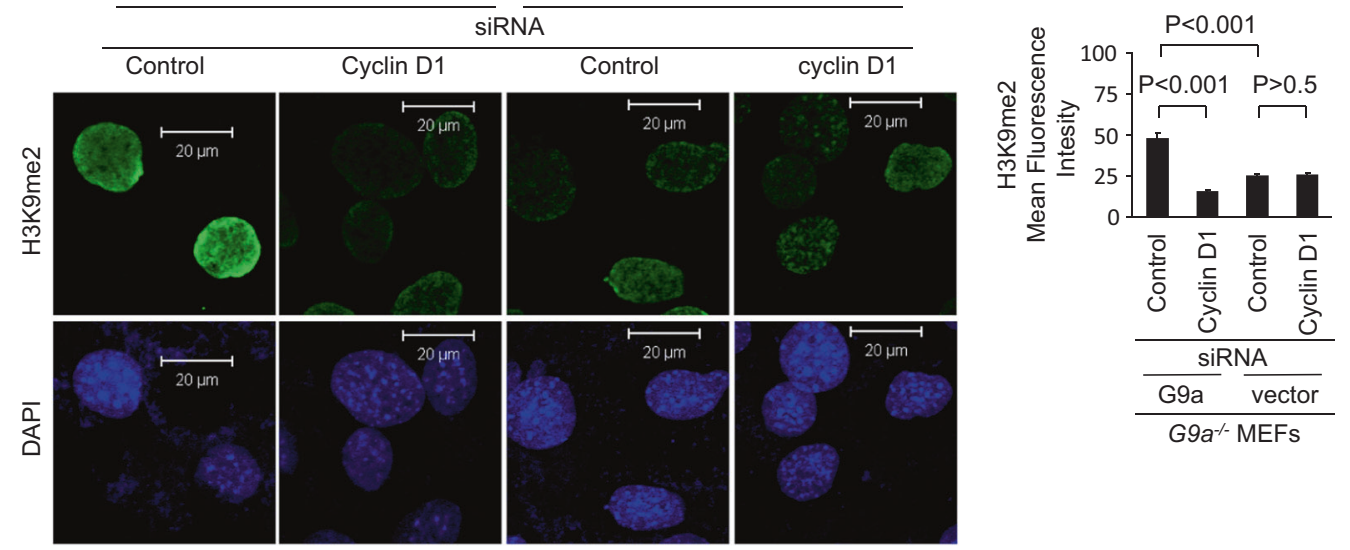

Fig. 4 G9a dimethylation of $\mathrm{H} 3 \mathrm{~K} 9$ requires endogenous cyclin D1. a, b Confocal microscopy of immunofluorescence for H3K9me2 (red) and nuclear staining with DAPI (blue) in $G 9 a^{f l f l}$ and $G 9 a^{-/-}$mouse embryonic fibroblasts (MEFs), and $G 9 a^{-/-}$MEFs rescued with G9a ${ }^{\text {WT }}$ or vector control. Images show the reduction in $\mathrm{H} 3 \mathrm{~K} 9 \mathrm{me} 2$ in $G 9 a^{-/-}$ cells (a) and quantitative analysis was shown as mean \pm SEM (b). c Western blot for H3K9me2 and G9a in $G 9 a^{f l f l}$ and $G 9 a^{-/-}$MEFs. The $G 9 a^{f / f l}, G 9 a^{-1-}$, and $G 9 a^{-1-}$ MEFs rescued with G9a and vector control were assessed by western blot for H3K9me2. Lamin B1 was used as a protein loading control. S.E. shorter exposure, L.E. longer exposure. d Quantitation of $\mathrm{H} 3 \mathrm{~K} 9 \mathrm{me} 2$ is shown as mean \pm SEM for $N$ $=3$. e MCF-7 cells transduced with two individual shG9a and shGFP control were assessed by western blot for $\mathrm{H} 3 \mathrm{~K} 9 \mathrm{me} 2$, cyclin D1, and G9a. Lamin B1 was used as a protein loading control. f, g Confocal microscopy of immunofluorescence for $\mathrm{H} 3 \mathrm{~K} 9 \mathrm{me} 2$ (green) and nuclear staining with DAPI (blue) in $G 9 a^{-/-}$MEFs rescued with G9a WT vector control treated with cyclin D1 small interfering RNA. Images show the reduction in $\mathrm{H} 3 \mathrm{~K} 9 \mathrm{me} 2$ by cyclin D1 siRNA in $G 9 a^{-/}$plus G9a cells but not in $G 9 a^{-/-}$plus vector cells. Scale bar, $20 \mu \mathrm{m}(\mathbf{f})$ and quantitative analysis was shown as mean \pm SEM (g) 
A

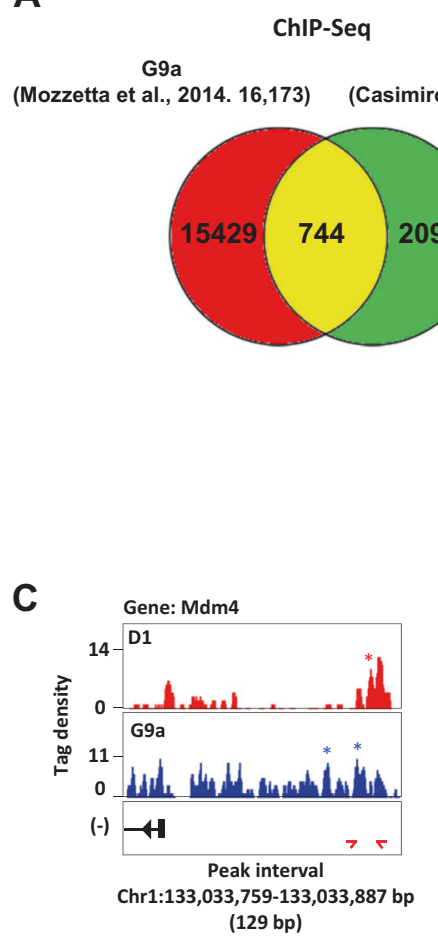

$\mathbf{F}$

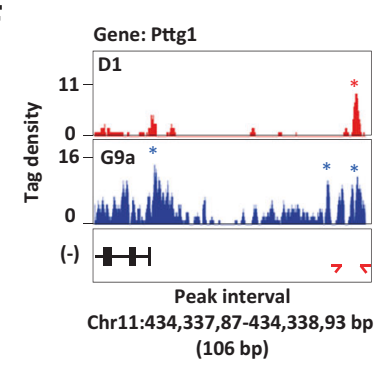

I

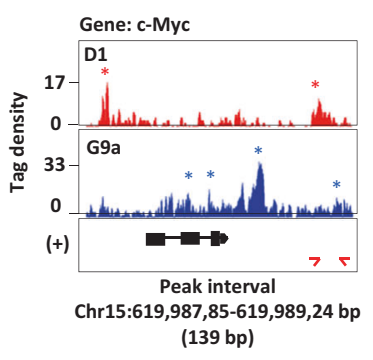

Cyclin D1

et al., 2012. 2,840)

B
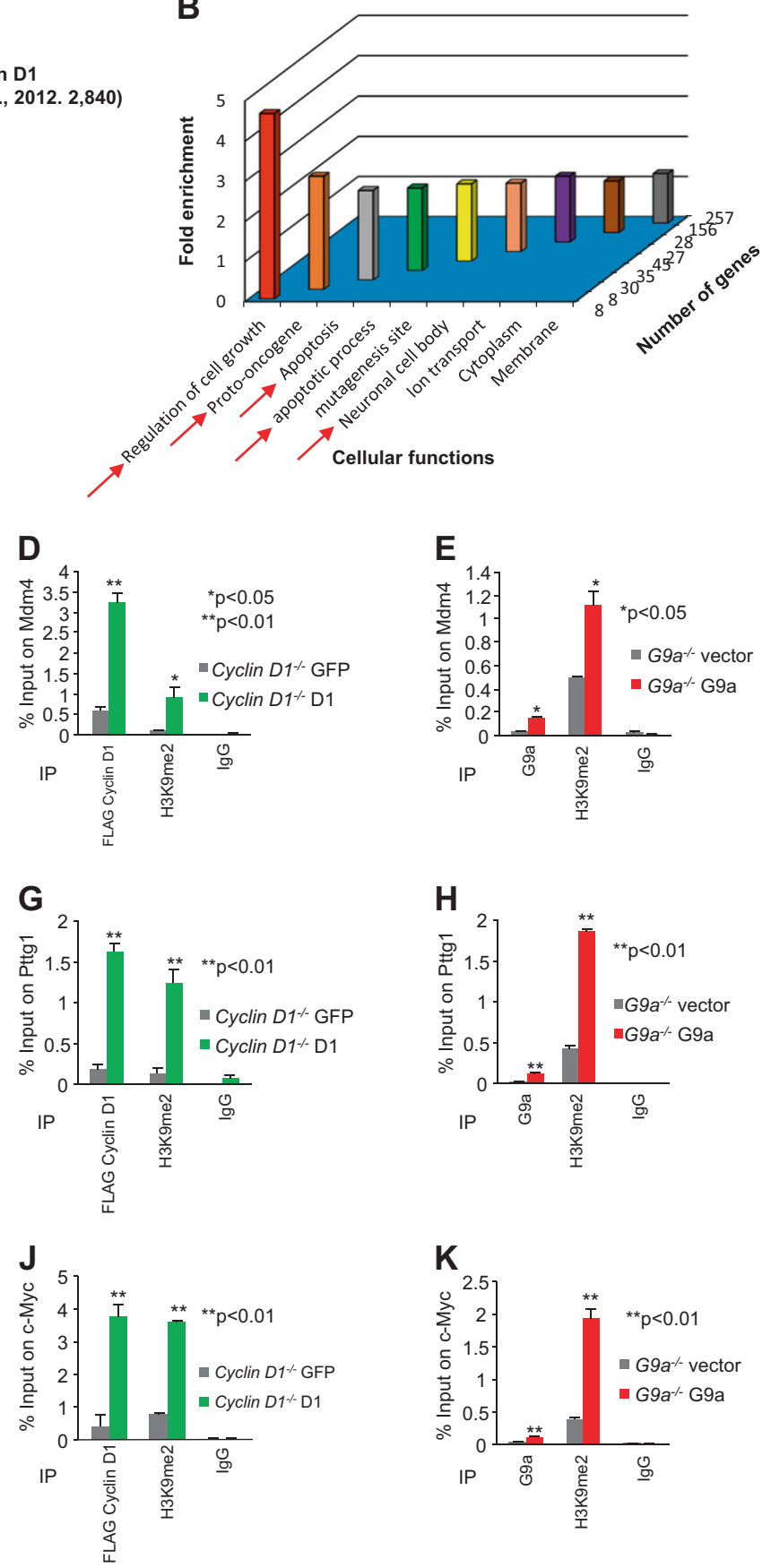

the Pttg1 gene cyclin D1 and G9a ChIP overlapped at a distal site coinciding with a Ctcf site (Fig. $5 \mathrm{f}-\mathrm{h}$ ). The same tag density profiles for ChIP-Seq are shown for cyclin D1 intervals (red) and G9a intervals (blue) in Fig. 5c, f. ChIP-Quantitative Polymerase Chain Reaction (ChIP-qPCR) assays were conducted to verify the ChIPSeq data of these genes in cyclin $\mathrm{Dl}^{-/-}$cells rescued with FLAG-cyclin D1 or vector control (Fig. 5d, g, j, green bars) and in $G 9 a^{-/-}$cells transduced with wild-type G9a or vector control (Fig. 5e, h, k, red bars). The primers used in ChIP-qPCR and the intervals and peaks in ChIP-Seq are shown in the Supplemental Table 1. Reintroduction of either cyclin D1 or G9a increased H3K9me2 bound to the same regions of these genes (Fig. $5 \mathrm{~d}, \mathrm{e}, \mathrm{g}, \mathrm{h}, \mathrm{j}, \mathrm{k}, * * P<$ $0.01, * P<0.05)$. Reintroduction of cyclin D1 into cyclin $D 1^{-/-}$cells demonstrated that cyclin D1 was recruited to each target gene examined, accompanied with increased H3K9me2 (Fig. 5d, g, j, Supplemental Fig. 5A, C, E, G, I, 
Fig. 5 G9a and cyclin D1 bind common regulatory regions of genes in chromatin immunoprecipitation (ChIP)-Seq. a Venn diagram depicting the overlapping intervals shared between cyclin D1 ChIP-Seq and G9a ChIP-Seq. b Gene Ontology (GO) biological function enrichment scores for overlapping terms for 744 genes common between cyclin D1 ChIP-Seq and G9a ChIP-Seq. $\mathbf{c}-\mathbf{k}$ Three genes (Mdm4, Pttg1, and $M y c$ ) were selected from the "oncogene" GO biological term and eight genes were selected from the "neuronal activities" GO term (Supplemental Figs. 4,5). c, f, i Depicted are tag density profiles for cyclin D1 intervals (red) and G9a intervals (blue) with respect to the identified genes. Profiles generated by Integrated Genome Browser are depicted for enriched regions binding G9a and the same region of cyclin D1 ChIP-Seq. Enriched intervals are designated by an * for cyclin D1 and a * for G9a. Tag density profiles are not drawn to scale $(\mathbf{c}, \mathbf{f}, \mathbf{i}) . \mathbf{d}, \mathbf{g}, \mathbf{j}$ Individual ChIP-qPCR analysis of target genes identified in ChIP-Seq. FLAG (FLAG-cyclin D1) ChIP-qPCR analysis of target genes in cyclin $D 1^{-1-}$ plus GFP vector vs cyclin $D 1^{-1-}$ plus cyclin $D 1^{\mathrm{WT}}$ rescue mouse embryonic fibroblasts (MEFs), and $\mathbf{e}, \mathbf{h}, \mathbf{k}$ G9a ChIP-qPCR of the same target genes in $69 a^{-1-}$ plus vector vs $69 a^{-/-}$plus G9a ${ }^{\text {WT }}$ rescued MEFs. H3K9me2 ChIP-qPCR is conducted in each cell type with IgG as control. Data are shown as mean \pm SEM for ChIP-qPCR of FLAG (FLAG-cyclin D1) and H3K9me2 for target genes identified in ChIP-Seq. Significant difference are shown as $* * P<0.01$ or $* P<0.05$ for cyclin $D 1^{-1-}$ plus GFP vector vs cyclin $D 1^{-/-}$plus cyclin $\mathrm{D} 1^{\mathrm{WT}}$ (d, $\mathbf{g}$, j). Mean \pm SEM is shown for ChIP-qPCR of G9a and H3K9me2 for $M m 44, P t t g 1$, and $c-M y c$ genes. Significant difference is shown as $* * P$ $<0.01$ or $* P<0.05$ for $G 9 a^{-/-}$plus vector vs $G 9 a^{-/-}$plus G9a ${ }^{\text {WT }}$ (e, $\mathbf{h}, \mathbf{k})$

$\mathrm{K}$ and M). Reintroduction of G9a into $G 9 a^{-/-}$cells resulted in increased G9a and increased $\mathrm{H} 3 \mathrm{~K} 9 \mathrm{me} 2$ at all target genes demonstrated by ChIP (Fig. 5e, h, k, Supplemental Fig. 5B, D, F, H, J, L and N).

\section{Cyclin D1 recruits G9a to target genes in the context of chromatin}

The G9a- and cyclin D1-binding regions for Pttg1 and cMyc were next assessed by ChIP in MCF-7 cells. As shown in MEFs, ChIP enrichment was identified for endogenous cyclin D1 and G9a (Fig. 6a, b). We next assessed the role of endogenous cyclin D1 in regulating the expression of the representative target genes shown to bind G9a and cyclin D1 in ChIP-qPCR and ChIP-Seq. Cyclin D1 siRNA transduction of MCF-7 cells reduced cyclin D1 abundance by western blotting (Fig. 6c), and consistent with a model in which endogenous cyclin D1 maintained expression of the genes identified, cyclin D1 siRNA reduced basal and estradiol-induced expression of the target genes ( $M d m 4$, Pttgl, and $c-M y c)$ (Fig. 6d-f). In order to determine whether cyclin D1 augmented G9a function by enhancing recruitment of G9a to target genes in the context of chromatin, cyclin $\mathrm{DI}^{-1-}$ MEFs were stably transduced with the cyclin D1 expression vector and G9a ChIP was conducted for the target genes $(M d m 4, P t t g 1$, and $c-M y c)$. The reintroduction of cyclin D1 enhanced recruitment of G9a to the target genes $\operatorname{Mdm} 4(n=3, P=0.01), P t t g 1 \quad(n=3, P<0.05)$, and $c-M y c(n=3, P<0.04)$ in ChIP assays (Fig. $6 \mathrm{~g}-\mathrm{i})$.

\section{Cyclin D1 and G9a are co-located at a subset of LAD- NL contacts}

As we had shown that cyclin D1 binds to G9a, we examined the functional significance of this association further. Large genomic regions termed "LADs" interact with the NL. It has been proposed that the LAD/NL interactions constrain the position of chromosomes contributing to the plasticity of chromosome folding [14]. Evidence from photoactivation and photobleaching experiments suggests that during the first two hours of the $\mathrm{G}_{1}$ phase of the cell cycle, chromatin is mobile over long distances $[37,38]$. G9a methylation of H3 lysine 9 contributes to the anchoring of NL-LAD to laminin [16]. We therefore examined the position of NL regions and compared these locations with the sites of cyclin D1 and G9a binding by ChIP-Seq (Supplemental Figure 6). NL regions were selected based on prior publications of NL in ESC (orange bars) and in MEFs (violet-/gray-colored bars) $[39,40]$. There are approximately 1189 LAD in MEFs [41]. There were 100 sites in which coincident binding of cyclin D1 and G9a occurred. Furthermore, the coincident binding of cyclin D1 and G9a was located at the edges of the LAD. We found 31 cyclin D1- and G9abinding genes to be located on the LAD edges by ChIPSeq $(P<0.001)$. The 31 cyclin D1- and G9a-binding genes were located near the edges site within a distance of +500 bp $(P<0.001)$. No binding of cyclin D1 and G9a was identified with any of the approximately 1800 genes located on the $\mathrm{X}$ chromosome.

In prior studies a subset of genes was shown to have G9a recruitment to their regulatory regions $(C D H 12, C F H R$, CYP2C19, and $L A D 1,2,6,8,63)$. Interestingly, cyclin D1and G9a-binding at these regions were shown to coincide with the NL. We therefore assessed the binding of G9a to several of these gene regions as previously described [14]. Consistent with prior studies, G9a associated in ChIP at the region of genes previously identified at the NL, and shown to be modified by $\mathrm{H} 3 \mathrm{~K} 9 \mathrm{me} 2$ in a G9a-dependent manner (Fig. 7a-h). Furthermore, we demonstrated that cyclin D1 was recruited to these same regions in Lamina-associated genes by ChIP-qPCR (Fig. 7a-h, cyclin D1 ChIP are shown as green bars).

\section{Cyclin D1 binding to G9a determines the interaction of LADs with NL}

The stochastic interaction of NL with LADs was associated with increased H3K9me2 status [14]. Although G9a methylation of H3K9 is important for the anchoring of NLLAD to laminin, the mechanisms governing the LAD-NL interaction are poorly understood. The ${ }^{\mathrm{m} 6} \mathrm{~A}$ (adenine-6methylation) tracer technology was developed to follow 
Fig. 6 G9a and cyclin D1 bind common regulatory regions of genes in chromatin immunoprecipitation (ChIP)-Seq in MCF-7 cells. a, b ChIP-qPCR analysis of target genes Pttgl and $c-M y c$ in MCF-7 cells for G9a and cyclin D1 binding. c Western blot for cyclin D1 in cyclin D1 siRNA-treated MCF-7 cells confirmed decrease of cyclin D1 abundance. $\mathbf{d}-\mathbf{f}$ Abundance of mRNA for $M d m 4$ (d), Pttgl (e), and $c-M y c$ (f) in MCF-7 with cyclin D1 siRNA or control is shown. Data of qPCR is mean \pm SEM for $n=3$. Eth ethanol, E2 estradiol. $\mathbf{g}-\mathbf{i}$ ChIP-qPCR analysis of target genes Pttgl and $c-M y c$ for G9a binding in cyclin D1 rescue cyclin $D 1^{-1-}$ mouse embryonic fibroblasts
A

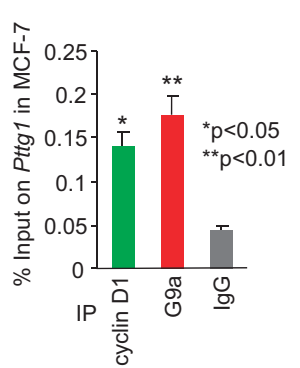

D

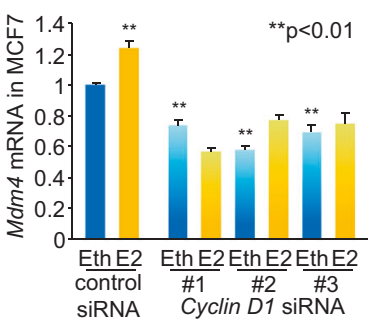

G
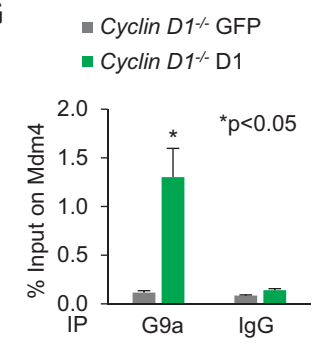

B

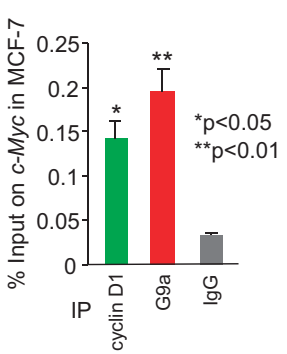

C

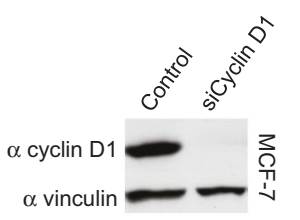

E

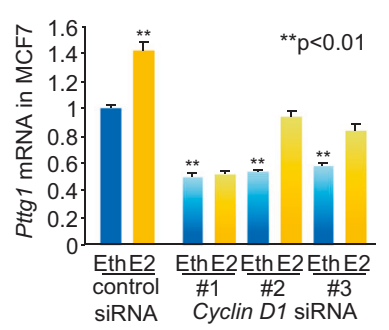

$\mathbf{F}$

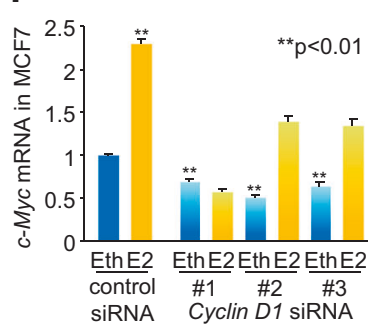

H

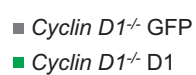

I

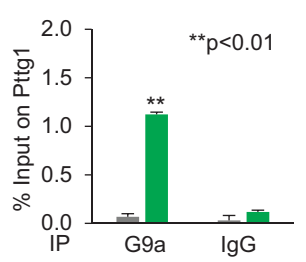

I

- Cyclin D1\% GFP - Cyclin D1\% D1

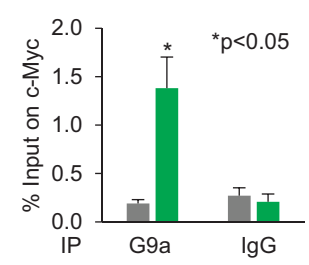

genomic-NL interactions at a single-cell level [14]. In this approach, adenine-6-methylation $\left({ }^{\mathrm{m} 6} \mathrm{~A}\right)$ is used to in vivo tag genomic regions in contact with nuclear proteins. In order to determine the role of cyclin D1 in the G9aregulated NL/LAD function [14], we deployed an HT1080derived clone in which the Dam-Lamin B and the ${ }^{\mathrm{m} 6} \mathrm{~A}$ tracer can be independently induced (Fig. 8a). In order to determine the role of cyclin D1, siRNA to cyclin D1 was deployed. After $72 \mathrm{~h}$ of cyclin D1 siRNA treatment, the ${ }^{\mathrm{m} 6} \mathrm{~A}$-tracer was induced upon removal of doxycycline using a tet-off system (Fig. 8b). The inducible Dam-Lamin B1 expression is dependent upon the fusion of a destabilization domain (DD), which ensures that Dam-Lamin B1 is rapidly targeted for proteasomal degradation in the absence of the small molecule called Shield1 [42].

In previous studies, neither Dam nor the fusion of DD affected the genome NL interactions [14]. The ${ }^{\mathrm{m} 6} \mathrm{~A}$-tracer was identified in the nuclear periphery $24 \mathrm{~h}$ after induction of Dam-Lamin B1 expression. The $24 \mathrm{~h}$ time point was used, because of the high resolution of ${ }^{\mathrm{m} 6} \mathrm{~A}$-tracer Lamin B1 interaction at that time point (Fig. 8b) [14]. The immunofluorescent labeling showed that the ${ }^{\mathrm{m} 6} \mathrm{~A}$-tracer in green, after induction of Dam-Lamin B1, co-localizes with H3K9me2 in red (Fig. 8c in yellow). In contrast, shG9a/
shGLP-transduced cells, and cyclin D1 siRNA-transduced cells, showed reduced ${ }^{\mathrm{m} 6} \mathrm{~A}$-tracer at the nuclear periphery and reduced co-localization with $\mathrm{H} 3 \mathrm{~K} 9 \mathrm{me} 2$ (Fig. 8c). Figure 8d shows the location of Lamin B1 at the nuclear periphery and the merged image of the ${ }^{\mathrm{m} 6} \mathrm{~A}$-tracer and Lamin B1 evidenced in control siRNA-treated cells (Fig. 8d, upper panel). Cyclin D1 siRNA decreased accumulation of ${ }^{\mathrm{m} 6} \mathrm{~A}-$ tracer at the nuclear periphery (Fig. 8d). shG9a/shGLP reduced the percentage of cells with the ${ }^{\mathrm{m} 6} \mathrm{~A}$-tracer ring by $>40 \%$ (Fig. 8e). Quantitative analysis of $n=415$ cells demonstrated a $50 \%$ reduction in the percentage of cells with ${ }^{\mathrm{m} 6} \mathrm{~A}$-tracer in cyclin D1 siRNA-treated cells (Fig. 8f, $P<0001)$. Together, these studies demonstrate that endogenous cyclin D1, like endogenous G9a, promotes $\mathrm{H} 3 \mathrm{~K} 9$ dimethylation and LAD-NL interaction.

\section{Cyclin D1 and G9a are overexpressed in $\mathrm{ERa}^{+}$breast cancer}

G9a is overexpressed in many types of cancer [43-45] and has been shown to augment tumorigenesis [46, 47], reviewed in [48]. Similarly, cyclin D1 overexpression augments breast cancer in transgenic mice $[49,50]$. We investigated whether cyclin D1 and G9a expression was 


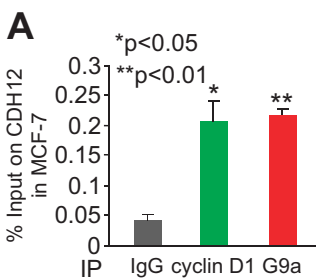

B
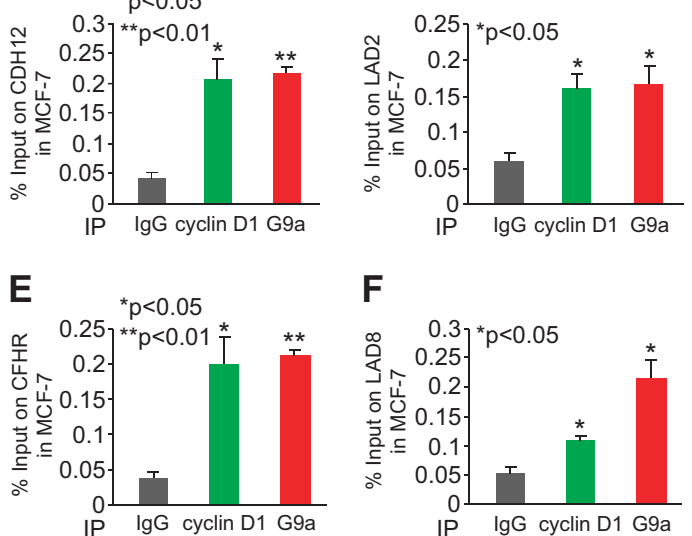

Fig. 7 G9a and cyclin D1 bind common regions of Lamina-associated genes in chromatin immunoprecipitation (ChIP). Individual ChIPqPCR analysis of Lamina-associated target genes in MCF-7 cells.

increased in human breast cancer and whether cyclin D1 correlated with increased G9a abundance in particular breast cancer subtypes. The relative abundance of cyclin D1 and G9a was correlated in normal breast epithelium $(P=$ 0.003, Supplemental Fig. 7A and B). Consistent with prior studies, cyclin D1 mRNA levels were increased in breast cancer compared with healthy breast tissue (Supplemental Fig. 7C). G9a was also increased in human breast cancer compared with healthy breast tissue (Supplemental Fig. 7D). G9a mRNA levels correlated with cyclin D1 mRNA levels in healthy breast tissue $(R=0.29, P=0.003)$ and $\mathrm{ER} \alpha^{+}$breast cancer samples $(R=0.27, P=8.07 \mathrm{e}-30)$. But no significant correlation was observed in $\mathrm{ER} \alpha^{-}$breast cancer patients (Supplemental Fig. 7E and F). Increased expression of either cyclin D1 or G9a was not significantly correlated with poor outcome breast cancer (Supplemental Fig. $7 \mathrm{G}$ and $\mathrm{H}$ ).

Together these data demonstrate that cyclin D1 binds and recruits $\mathrm{G} 9 \mathrm{a}$ to induce $\mathrm{H} 3 \mathrm{~K} 9$ dimethylation, which is known to promote NL-LAD interactions at the nuclear periphery (Supplemental Fig. 8). Cyclin D1 recruits G9a, which promotes $\mathrm{H} 3 \mathrm{~K} 9 \mathrm{me} 2$ at the promoter of target genes, which may thereby regulate gene expression and signaling.

\section{Discussion}

The current studies define novel functions for cyclin D1 determined through binding of the protein methyltransferase G9a. First, using G9a rescued $G 9 a^{-/-}$MEFs, we showed that endogenous cyclin D1 was required for G9a to induce H3K9me2. Second, in genome-wide analysis, $26.2 \%$ of cyclin D1-binding sites were found to be coincident for G9a binding $(P<0.01)$. Furthermore, there was enrichment for cyclin D1 and G9a binding at the edges of LADs. Third, we
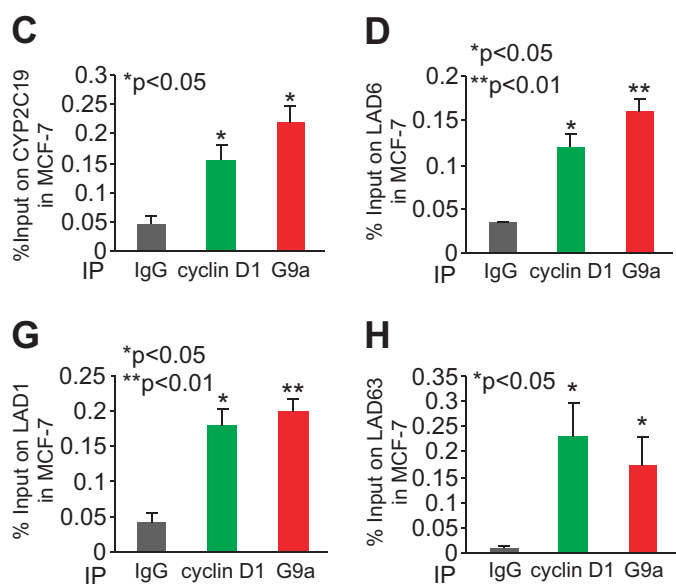

Cyclin D1 and G9a ChIP-qPCR analysis of target is shown as mean \pm SEM for $n=3$. a CDH12, b LAD2, c CYP2C19, d LAD6, e CFHR, $\mathbf{f}$ LAD8, g LAD1, and $\mathbf{h}$ LAD63

showed endogenous cyclin D1 augments recruitment of G9a to target genes in ChIP (Pttgl and Mdm4). Fourth, using an adenine-6-methylation tracer, we demonstrated the requirement for endogenous cyclin D1 in maintaining the G9a function of $\mathrm{H} 3 \mathrm{~K} 9 \mathrm{me} 2$ visualizing incorporation at NLLAD sites. Collectively, these studies demonstrate a novel chaperone function for cyclin D1 to recruit G9a and thereby augment $\mathrm{H} 3 \mathrm{~K} 9$ dimethylation.

Analysis of cyclin D1 and G9a ChIP-Seq demonstrated a significant overlap in binding to common genes. The GO terms corresponding to the genes bound by both cyclin D1 and G9a included regulation of cell growth, apoptosis, and neural function. G9a is known to be overexpressed in a variety of malignancies [43-45] and enhances tumorigenesis [46, 47]. Similarly, cyclin D1 is overexpressed in malignancies and enhances mammary tumorigenesis $[49,50]$. Cyclin D1 promotes neurite extension $[34,35]$ and using anti-sense, cyclin D1 was shown to be essential for Nerve Growth Factor (NGF)-induced neurite extension [34]. Cyclin D1 and G9a are expressed in the developing central nervous system [51] and participate in neurogenesis [36], therefore an additional seven genes were selected from the neurogenesis function. At each of the genes assessed, cyclin D1 augmented $\mathrm{H} 3 \mathrm{~K} 9 \mathrm{me} 2$ at the target gene in chromatin. Furthermore, cyclin D1 was shown to augment G9a recruitment to target genes. Mutational analysis herein demonstrated the binding and augmentation of G9a KMT function was independent of the cyclin D1 kinase function, consistent with recent studies that showed cyclin D1 induced mammary tumorigenesis independently of its kinase function $[30,50]$. The mechanisms by which cyclin D1 governs neurogenesis is not known, however based on genetic deletion studies in the mouse, may involve the Notch pathway [52]. Cyclin D1 activates Notch signaling by enhancing $\gamma$ secretase activity [53], and the neural stem 
A

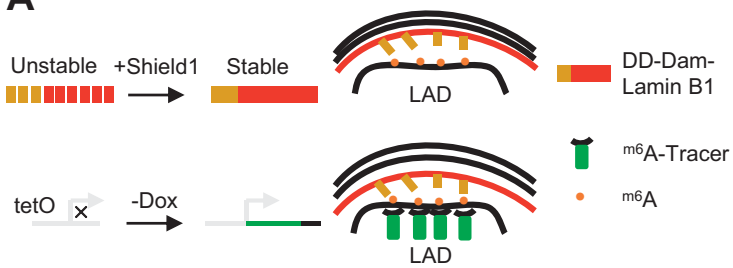

B

Clone \#3, HT1080 with DDDam-Lamin B1 and m6A-Tracer

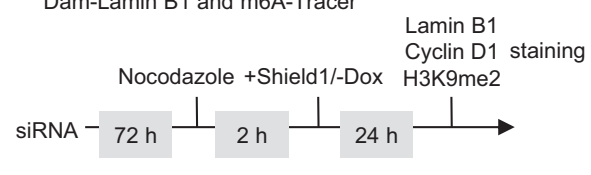

C
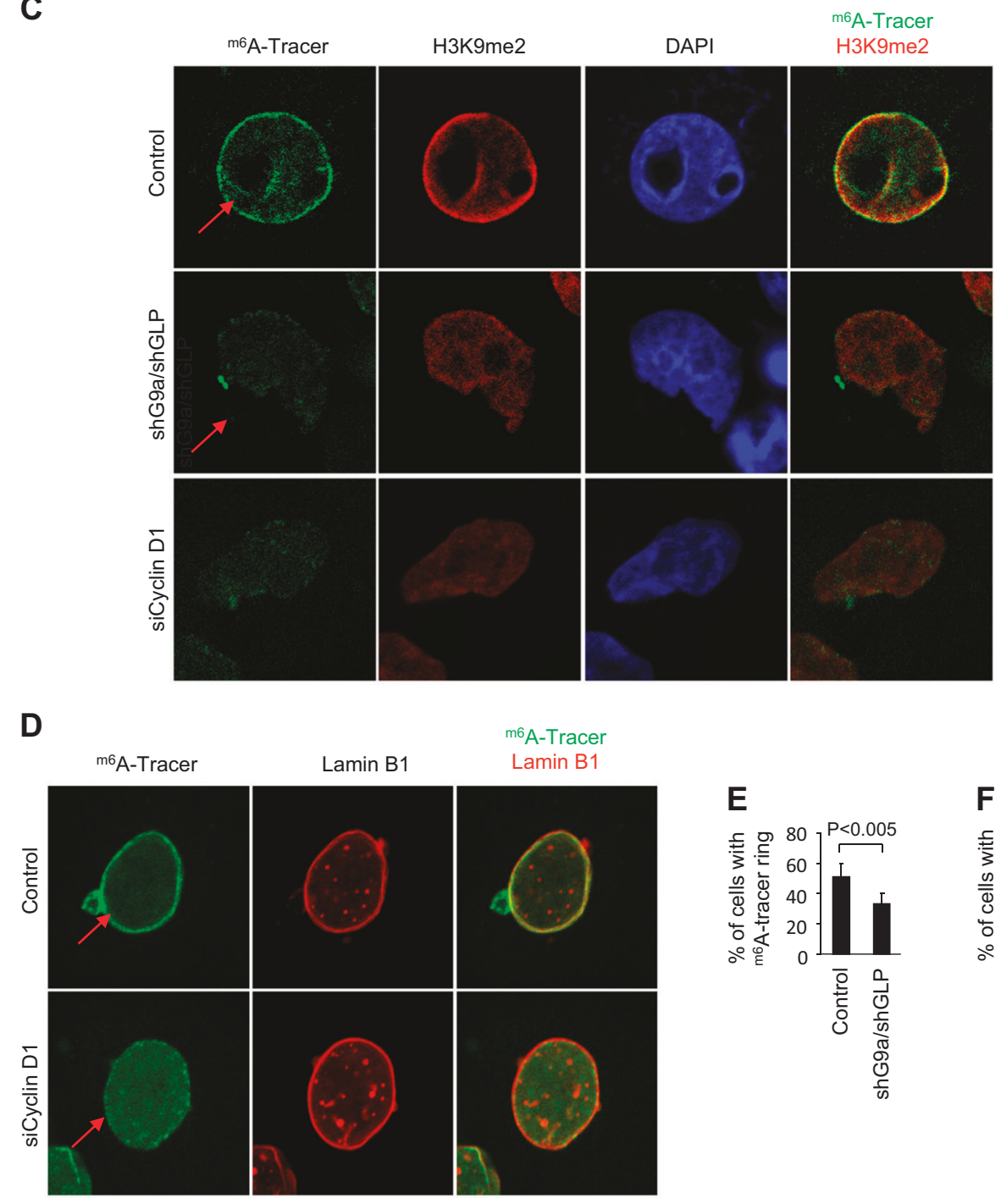

${ }^{\mathrm{m} 6} \mathrm{~A}-\mathrm{Tracer}$ Lamin B1

E

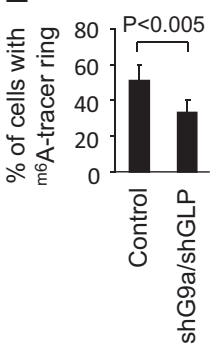

$\mathbf{F}$

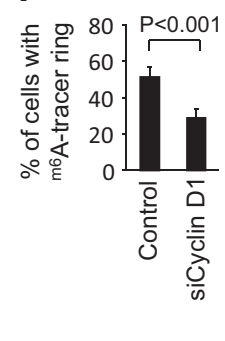

Fig. 8 Cyclin D1 determines accumulation of G9a-mediated nuclear lamina interactions at the nuclear periphery. a Illustration of the inducible ${ }^{\mathrm{m} 6} \mathrm{~A}$-tracer/Dam-lamin B1 system in the HT1080 cell line stably expressing the Shield1-inducible Dam-Lamin B1 and the Tetoff ${ }^{\mathrm{m} 6} \mathrm{~A}$-tracer (known as the line clone 3). Inducible Dam-Lamin B1 expression was established by the fusion of a destabilization domain (DD), which causes Dam-Lamin B1 to be rapidly targeted for proteasomal degradation unless the protein is shielded by the synthetic small molecule Shield1.The induction of ${ }^{\mathrm{m} 6} \mathrm{~A}$-tracer is based on the Tet-Off system, where the removal of doxycycline (Dox) results in the activation of transcription. b Schematic representation of the experimental protocol. c Confocal microscopy images showing both G9a shRNA/GLP shRNA and cyclin D1 siRNA decreases
H3K9me2 staining (red) in H1080 cells. d Representative confocal microscopy images showing cyclin D1 siRNA decreases accumulation of ${ }^{\mathrm{m} 6} \mathrm{~A}$-tracer signal (green) at the nuclear periphery after induction of Dam-Lamin B1. Lamin B1 staining is shown in red. e Quantitative analysis of ${ }^{\mathrm{m} 6} \mathrm{~A}$-tracer incorporation at the nuclear periphery after induction of Dam-Lamin B1 expression shown as \% of cells incorporating tracer for $n>200$ separate cells for shG9a/shGLP treatment and its vector control. Data are percentage $\pm 95 \%$ confidence interval (CI). f Quantitative analysis of ${ }^{\mathrm{m} 6} \mathrm{~A}$-tracer incorporation at the nuclear periphery shown as $\%$ of cells incorporating tracer for $n>400$ separate cells cyclin D1 siRNA treatment as well as its control. Data are percentage $\pm 95 \%$ CI 
cell-promoting function of cyclin D1 is distinct from its cell cycle function [54]. Whether the augmentation of G9a function by cyclin D1 contributes to tumorigenesis and neurogenesis remains to be determined.

The regulation of gene expression and the maintenance of genomic integrity is influenced by interphase chromosomes architecture. The mechanisms governing chromosomal positioning and architecture is poorly understood. The NL interacts with multiple LAD, which cover $35-40 \%$ of the mammalian genome, thereby restraining the position of chromosomes. The functional significance of the interaction between cyclin D1 and G9a included the requirement for endogenous cyclin D1 to maintain the G9a-dependent genome-NL interactions [14]. As the abundance of cyclin D1 is regulated during the cell cycle and by diverse oncogenic and mitogenic signals [23], the current studies provide a potential mechanism by which the multiple dynamic inputs that govern cyclin D1 abundance may, in turn, influence chromosomal architecture.

The current studies demonstrate cyclin D1 functions to recruit G9a and thereby induce dimethylation of $\mathrm{H} 3 \mathrm{~K} 9$ as shown by immunofluorescence and western blotting. Furthermore, cyclin D1, recruited in the context of chromatin, induced $\mathrm{H} 3 \mathrm{~K} 9 \mathrm{me} 2$. Several distinct enzyme complexes are either recruited by cyclin D1 ${ }^{\mathrm{WT}}$ in the context of chromatin including SUV39H1, HP1 $\alpha$, HDAC, and p300 [26, 29], or in the case of a cyclin D1 synthetic mutant (T286A), associates with PRMT5 [55]. G9a has an ability to methylate additional non-histone substrates, and it will be of interest to determine whether cyclin D1 is capable of augmenting these additional G9a-mediated functions. $\mathrm{H} 3 \mathrm{~K} 9 \mathrm{me} 2$, which is an abundant histone mark maintained by several enzymes in addition to G9a (SETDB1 and SUV39H1), was maintained by endogenous cyclin D1. Whether G9a is the only H3K9 dimethylase bound by cyclin D1 remains to be determined. Further analysis of the genes targeted by G9a and cyclin D1 that govern chromosomal segregation and oncogenesis may provide important mechanistic insights into these fundamental processes.

\section{Materials and methods}

\section{Plasmids}

The pBIND plasmids expressing GAL4-tagged cyclin D1 wild type and mutations were as described previously [56]. The pcDNA3.1 plasmids encoding FLAG-tagged G9a ${ }^{\text {WT }}$ and deletion mutations were obtained from Dr. Eiji Hara (Cancer Institute, Japanese Foundation for Cancer Research, Tokyo, Japan) [57]. The pLKO lentiviral plasmid vectors of human G9a shRNA and GLP shRNA were purchased from Sigma.

\section{Cell culture and reagents}

MCF-7 and HEK 293T cell lines were from the American Type Culture Collection (ATCC, Manassas, VA). Cyclin $D 1^{+/+}$MEFs, cyclin $D 1^{-/-}$MEFs, cyclin $D 1^{-/-}$MEFs rescued with cyclin $\mathrm{D} 1^{\mathrm{WT}}$, cyclin $\mathrm{D} 1^{\mathrm{KE}}$ mutant, or vector control were as described before [58]. The $G 9 a^{f l / f l}$ MEFs and $G 9 a^{-1-}$ MEFs were a generous gift from Dr. Alexander Tarakhovsky (The Rockefeller University, New York) [59]. The HT1080 cell line stably expressing the Shield1inducible Dam-Lamin B1 and the Tet-off ${ }^{\mathrm{m} 6} \mathrm{~A}$-tracer (known as the line clone 3 ) was provided by Dr. Bas van Steensel (Netherland Cancer Institute, Amsterdam, Netherland) [14]. The restriction endonuclease DpnI cuts the sequence $\mathrm{G}^{\mathrm{m} 6} \mathrm{ATC}$ ( ${ }^{\mathrm{m} 6} \mathrm{~A}$ is short for adenine-6-methylation) but not GATC. The truncation mutation, a C-terminal fragment of 109 amino acids of $D p n I$ fused to enhanced green fluorescent protein (EGFP) is referred as ${ }^{\mathrm{m} 6} \mathrm{~A}$-tracer. The ${ }^{\mathrm{m} 6} \mathrm{~A}$-tracer signal is reduced beyond detection (EGFP detected using microscopy) after $24 \mathrm{~h}$ incubation with 50 ng/ml doxycycline (Research Products International Corp. Mount Prospect, IL). Cells were cultured in Dulbecco's modified Eagle's medium (DMEM) containing streptomycin and penicillin (100 mg of each/liter) and $10 \%$ fetal bovine serum (FBS). To promote stability of long-term culture, the clone 3 of HT1080 cells were maintained in $400 \mu \mathrm{g} / \mathrm{ml} \mathrm{G} 418$ (Santa Cruz Biotechnology) and $2 \mu \mathrm{g} / \mathrm{ml}$ puromycin (Sigma).

MCF-7 and HEK 293T were recently authenticated by ATCC. The MEFs generated by the Pestell lab were authenticated by IDEXX Bioresearch. All of the cells were tested for Mycoplama contamination using the ATCC Universal Mycoplasma Detection Kit.

\section{siRNA knockdown of endogenous cyclin D1}

The siRNAs specifically targeting human cyclin D1 mRNA (Hs_CCND_1, Hs_CCND_2, and Hs_CCND_3), purchased from Qiagen, were used for suppressing endogenous cyclin D1 expression in HT1080 cells. For suppression of endogenous cyclin D1 expression in $G 9 a^{-/-}$MEFs rescued with wild-type G9a or vector control, mouse Ccnd1_2 FlexiTube siRNAs (Catalog \#SI00943642) specifically targeting mouse cyclin D1 mRNA were also purchased from Qiagen. The cyclin D1 siRNAs or negative control siRNA (Qiagen) were transfected into the cells with the Lipofectamine 2000 (Invitrogen, Carlsbad, CA) according to the manufacturer's instruction. For HT1080 cells, which stably expressing the Shield1-inducible Dam-Lamin B1 and the Tet-off ${ }^{\mathrm{m} 6} \mathrm{~A}$-tracer, after transfection, the cells were sequentially treated with $10 \mu \mathrm{M}$ Nocodazole (Sigma) for 72 $\mathrm{h}$ and $0.5 \mu \mathrm{M}$ Shield1 (Clontech) in DMEM with $10 \%$ tetracycline-free FBS for $2 \mathrm{~h}$ to induce Dam-Lamin B1 and 
${ }^{\mathrm{m} 6} \mathrm{~A}$-tracer expressing. The immunofluorescence staining was performed another $24 \mathrm{~h}$ later. For $G 9 a^{-/-}$MEFs, immunofluorescence staining was processed $72 \mathrm{~h}$ later after siRNA transfection.

\section{Immunofluorescence staining}

Immunofluorescence staining was conducted as described previously [56]. The cells in four-well chamber slides were fixed for $10 \mathrm{~min}$ at room temperature (RT) with $4 \%$ paraformaldehyde, and subsequently with cold methanol at -20 ${ }^{\circ} \mathrm{C}$ for $5 \mathrm{~min}$. The slides were then treated with $0.2 \%$ Triton $\mathrm{X}-100$ for $5 \mathrm{~min}$ at RT and blocked with $2 \%$ bovine serum albumin overnight at $4{ }^{\circ} \mathrm{C}$. For $\mathrm{H} 3 \mathrm{~K} 9 \mathrm{me} 2$ and cyclin D1, G9a and cyclin D1 co-staining in MEFs the primary antibodies used were mouse monoclonal anti-H3K9me2 (ab1220) (Abcam Inc.) (1/800), mouse monoclonal antiG9a (clonal A8620A) (PP-A8620A-00) (R\&D System) (1/ 500 ), and rabbit polyclonal anti-cyclin D1 (clone H-295) (sc-753) (Santa Cruz Biotechnology, Santa Cruz, CA) (1/ 200). The secondary antibodies used were Alexa Fluor 568conjugated goat anti-mouse immunoglobulin G (IgG) (Molecular Probes, Inc.) (1/500) and Alexa Fluor 647conjugated $\mathrm{F}\left(\mathrm{ab}^{\prime}\right) 2$ fragment of goat anti-rabbit $\mathrm{IgG}$ (Molecular Probes, Inc.) (1/500). For HT1080 immunostaining the primary antibodies used were mouse monoclonal anti-cyclin D1 (clone DCS-6) (sc-20044) (Santa Cruz Biotechnology, Santa Cruz, CA) (1/200), rabbit polyclonal antiLamin B1 (ab16048) (Abcam Inc.) (1/900), and mouse monoclonal anti-H3K9me2 (ab1220) (Abcam Inc.) (1/800). The secondary antibodies used were rhodamine-conjugated $\mathrm{F}\left(\mathrm{ab}^{\prime}\right) 2$ fragment of goat anti-rabbit IgG (Jackson Immuno Research Laboratories, Inc.) (1/500) and Alexa Fluor 633conjugated $\mathrm{F}\left(\mathrm{ab}^{\prime}\right) 2$ fragment of goat anti-mouse $\mathrm{IgG}$ (Molecular Probes, Inc.) (1/500). The samples were visualized on a Zeiss LSM 510 META Confocal Microscope with a $\times 63$ objective.

\section{Immunoprecipitation and western blotting}

HEK 293T cells was co-transfected with pBIND-FLAGG9a and pcDNA3.1-GAL4-cyclin D1. The transfected cells were lysed $48 \mathrm{~h}$ later in IP buffer $(10 \mathrm{mM}$ Tris- $\mathrm{HCl}$ at $\mathrm{pH}$ 7.4, $150 \mathrm{mM} \mathrm{NaCl}, 1 \mathrm{mM}$ EDTA, $1 \mathrm{mM}$ EGTA, $1 \%$ Triton X-100, 0.5\% IGEPAL CA-630, 10\% glycerol, $0.2 \mathrm{mM}$ sodium orthovanadate, $0.1 \mathrm{mM}$ phenylmethylsulfonyl fluoride, $10 \mu \mathrm{g} / \mathrm{ml}$ aprotinin, $1 \mu \mathrm{g} / \mathrm{ml}$ leupeptin, and $1 \mu \mathrm{g} / \mathrm{ml}$ pepstatin). For each IP, $1 \mathrm{ml}$ cell lysate containing $1 \mathrm{mg}$ protein was incubated overnight with $10 \mu$ anti-FLAG M2agarose beads (A2220, Sigma-Aldrich) at $4{ }^{\circ} \mathrm{C}$. The immunoprecipitates were washed five times with IP buffer, and lysed in $20 \mu \mathrm{l}$ of $\times 2$ sample buffer. The immunoprecipitates and the corresponding lysates containing $50 \mu \mathrm{g}$ protein were analyzed by western blotting as previously described [58]. Antibodies that were used for western blotting included: mouse anti-FLAG antibody (M2, F-3165, Sigma-Aldrich), anti-vinculin antibody (V9131, Sigma-Aldrich), mouse anti-cyclin D1 antibody (DCS-6, SC-20044, Santa Cruz), rabbit anti-Lamin B1 (ab16048, Abcam), mouse anti-G9a (clonal A8620A) (PP-A8620A00) (R\&D System), mouse anti-H3K9me2 (ab1220, Abcam), and rabbit anti-G9a antibody (Catalog \# 07-551, Millipore).

\section{ChIP assay}

ChIP analysis was performed using Magna ChIP kits (Millipore) according to the manufacturer's instruction. The following antibodies were used in ChIP: mouse monoclonal anti-FLAG (M2) (F-3165, Sigma-Aldrich) (for FLAGcyclin D1), mouse anti-G9a (clonal A8620A) (PPA8620A-00) (R\&D System), rabbit anti-G9a (clonal C6H3) (Cell signaling), and mouse anti-H3K9me2 (ab1220) (Abcam Inc.). For a negative control, mouse IgG was from the Magna ChIP kits (Millipore). SYBR Green PCR kit (Invitrogen) was used in the ChIP-real time PCR (ChIPqPCR). The primers used in ChIP-qPCR are shown in the Supplemental Table 1.

\section{Generation of cyclin D1 knockout mice and immunohistochemistry staining}

The Animal protocol used in this study was approved by the Institutional Animal Care \& Use Committee at Thomas Jefferson University. C57BL/6J cyclin $D 1^{f l / f}$ mice were a kind gift from Dr. Piotr Sicinski (Dana-Farber Cancer Institute, Boston, MA). C57BL/6J Rosa26-CreERT2 mice, which express the tamoxifen-inducible CreERT2 fusion protein were from Dr. Thomas Ludwig (Columbia University, New York, NY). Cyclin D $1^{f / f t}$-Rosa $26^{\text {CreERT2/CreERT2 }}$ mice were generated by crossing cyclin $D l^{f / f l}$ mice with Rose26-Cre-ERT2 mice. Cyclin D1 knockout mice were

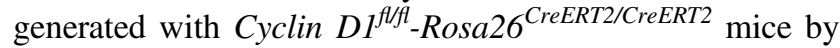
intraperitoneal injection of tamoxifen $(1 \mathrm{mg} / 200 \mu \mathrm{l}$ sunflower seed oil) for 5 days. Cyclin D1 ${ }^{w t / w t}-$ Rosa $26^{\text {CreERT2/ }}$ CreERT2 mice were used as control. Mammary glands from these mice were collected 4 weeks after IP injection of tamoxifen. Immunohistochemistry staining was conducted on paraffin-embedded mammary gland sections. The primary antibodies used were mouse monoclonal anti-cyclin D1 (clone DCS-6) (sc-20044) (Santa Cruz Biotechnology, Santa Cruz, CA), rabbit polyclonal anti-G9a (clone C6H3) (Cell Signaling Technology, Inc, Danvers, MA), and mouse monoclonal anti-H3K9me2 (ab1220) (Abcam Inc.). 
Cyclin D1- and G9a-bound regions by ChIP-Seq and related biological function pathway analysis

Genomic DNA regions bound by cyclin D1 [30] were compared to those bound by G9a as determined via ChIPSeq analysis [33]. We retrieved genomic locations of G9a peaks from the GEO database (accession number GSM1215219). Cyclin D1 peaks were identified using MACS v1.4 software with the following parameters: shiftsize 50 -nomodel [60]. We identified 6834 cyclin D1 peaks at the false discovery rate cutoff of $5 \%$. The average size of a G9a-enriched region (peak) is $800 \mathrm{bp}$. The average size of a cyclin D1-enriched region (peak) is $400 \mathrm{bp}$. A cyclin D1 and G9a peaks were deemed to be co-localized at a locus when the enriched regions shared overlapping nucleotide binding. Using this criterion, we found that 755 of cyclin D1 peaks overlap G9a peaks genome-wide. In all, 744 genes corresponding with these 755 peaks were located within $25 \mathrm{~kb}$ of gene transcription start sites [61-63]. The common genes between the two sets were queried for biological function using the PANTHER classification system [64, 65] of GO terms within Database for Annotation, Visualization and Integrated Discovery (DAVID) [66, 67]. GO-enrichment analysis was conducted using PANTHER (Protein ANalysis THrough Evolutionary Relationship). The PANTHER Classification System of GO terms involved in a Biological Process was used to cluster genes based on function. The enrichment score was based on the EASE scores; a modified Fisher exact $P$-value for gene enrichment analysis. The following parameters within DAVID were kept at default; EASE threshold $=0.1$ and count threshold $=2$. PANTHER pathways ( 9 total) were chosen based on Fisher exact $P$-value $>0.05$. Select genes were further analyzed using the Integrated Genome browser (Affymetrix) to depict the cyclin D1 and G9a tracks $[66,67]$.

\section{Analysis of G9a- and cyclin D1 DNA-bound regions at chromosomal locations and to LAD}

A list of genes was generated for G9a- and cyclin D1-bound genomic locations based on prior published ChIP-Seq data $[30,33,41]$. A sequentially expanding list of nearestneighbor genes was compared between G9a and cyclin D1 ChIP-Seq data by making iterative expansions of the associated interval $(500 \mathrm{bp}, 1 \mathrm{~kb}, 2 \mathrm{~kb}, 5 \mathrm{~kb}$, and $10 \mathrm{~kb})$. We obtained the list of G9a associated Ensembl gene IDs from Mozzetta et al. [33], supplementary table (http://www.cell. com/cms/attachment/2038986201/2052742122/mmc2.

xlsx), column E (G9a ChIP-Seq in TT2 mESC). The list of cyclin D1-associated genes was based on overlapping the cyclin D1 interval coordinate data to the NCBI proteincoding genes [30]. Genes found under cyclin D1 intervals were validated by comparing the cyclin D1 gene sets obtained by two different researchers using two different methods. Both methods returned the same core genes, with the newer method returning more genes (478). Both methods found the overlap of cyclin D1/G9a genes statistically significant. The first method was the NCBI overlap method just described. The second method found Ensembl genes under or within $10 \mathrm{~kb}$ of the cyclin D1 intervals using the Ensembl Release 67 from May 2012 because the cyclin D1 interval data were mapped onto the older assembly. The additional genes from the second method were likely found because there was no loss from a NCBI-to-Ensemble gene ID translation when comparing G9a Ensembl IDs and cyclin D1 NCBI vs Ensembl gene IDs. To obtain the list of genes that possess both overlapping genes of cyclin D1 and G9a, we analyzed the intersection of G9a and cyclin D1 gene sets. Statistical significance of the overlap was conducted using hypergeometric test $[68,69]$. The intersecting cyclin D1 and G9a protein-coding genes were mapped to prior published LAD coordinates for mESCs and fibroblasts [70, 71].

\section{Statistical analysis}

The statistical significance of mean difference was determined with two-tailed Student's $t$-test. The statistical significance of two sample proportions was determined with two-tailed two-sample $z$-test.

\section{Disclaimer}

The Pennsylvania Department of Health specifically disclaims responsibility for analyses, interpretations, or conclusions

Acknowledgements We are very grateful to Drs. Alexander Tarakhovsky (Laboratory of Immune Cell Epigenetics and Signaling, Rockefeller University, New York, NY), Thomas Ludwig (Columbia University, New York, NY), and Bas van Steensel (Division of Gene Regulation, Netherlands Cancer Institute, Amsterdam, the Netherlands) for providing materials used in this study. The authors thank Julien Pontis (University Paris Diderot, Paris), for providing the ChIPSeq data for G9a.

Funding This work was supported in part by R01CA70896, R01CA75503, and R01CA86072 (RGP). This project was funded in part from the Dr. Ralph and Marian C. Falk Medical Research Trust (RGP), a grant from the Breast Cancer Research Foundation (RGP), and a grant from the Pennsylvania Department of Health (RGP).

Authors' contributions RGP, ZL, and XJ conceived the study and designed experiments. ZL, XJ, GD, SK and XJ performed experiments. ZL, XJ, GD, MCC, DVK, AT, WD, IC, AJ, and RGP analyzed the data. RGP, ZL, XJ and GD wrote the paper. RGP supervised the studies. 


\section{Compliance with ethical standards}

Conflict of interest RGP holds ownership interests in, and serves as $\mathrm{CSO} /$ Founder of, the biopharmaceutical companies LightSeed, Inc. and is CMO and Board member of CytoDyn. RGP holds ownership interests (value unknown) in several issued and submitted patent applications. The remaining authors declare that they have no conflict of interest.

Publisher's note: Springer Nature remains neutral with regard to jurisdictional claims in published maps and institutional affiliations.

Open Access This article is licensed under a Creative Commons Attribution 4.0 International License, which permits use, sharing, adaptation, distribution and reproduction in any medium or format, as long as you give appropriate credit to the original author(s) and the source, provide a link to the Creative Commons license, and indicate if changes were made. The images or other third party material in this article are included in the article's Creative Commons license, unless indicated otherwise in a credit line to the material. If material is not included in the article's Creative Commons license and your intended use is not permitted by statutory regulation or exceeds the permitted use, you will need to obtain permission directly from the copyright holder. To view a copy of this license, visit http://creativecommons. org/licenses/by/4.0/.

\section{References}

1. Dawson MA, Kouzarides T. Cancer epigenetics: from mechanism to therapy. Cell. 2012;150:12-27.

2. Rea S, Eisenhaber F, O'Carroll D, Strahl BD, Sun ZW, Schmid $\mathrm{M}$, et al. Regulation of chromatin structure by site-specific histone H3 methyltransferases. Nature. 2000;406:593-9.

3. Collins RE, Tachibana M, Tamaru H, Smith KM, Jia D, Zhang X, et al. In vitro and in vivo analyses of a Phe/Tyr switch controlling product specificity of histone lysine methyltransferases. J Biol Chem. 2005;280:5563-70.

4. Kubicek S, O'Sullivan RJ, August EM, Hickey ER, Zhang Q, Teodoro ML, et al. Reversal of H3K9me2 by a small-molecule inhibitor for the G9a histone methyltransferase. Mol Cell. 2007;25:473-81.

5. Tachibana M, Ueda J, Fukuda M, Takeda N, Ohta T, Iwanari H, et al. Histone methyltransferases G9a and GLP form heteromeric complexes and are both crucial for methylation of euchromatin at H3-K9. Genes Dev. 2005;19:815-26.

6. Nozawa RS, Nagao K, Masuda HT, Iwasaki O, Hirota T, Nozaki $\mathrm{N}$, et al. Human POGZ modulates dissociation of HP1alpha from mitotic chromosome arms through Aurora B activation. Nat Cell Biol. 2010;12:719-27.

7. Ogawa H, Ishiguro K, Gaubatz S, Livingston DM, Nakatani Y. A complex with chromatin modifiers that occupies E2F- and Mycresponsive genes in G0 cells. Science. 2002;296:1132-6.

8. Nishio H, Walsh MJ. CCAAT displacement protein/cut homolog recruits G9a histone lysine methyltransferase to repress transcription. Proc Natl Acad Sci USA. 2004;101:11257-62.

9. Collins R, Cheng X. A case study in cross-talk: the histone lysine methyltransferases G9a and GLP. Nucleic Acids Res. 2010;38:3503-11.

10. Sampath SC, Marazzi I, Yap KL, Krutchinsky AN, Mecklenbrauker I, Viale A, et al. Methylation of a histone mimic within the histone methyltransferase G9a regulates protein complex assembly. Mol Cell. 2007;27:596-608.

11. Rathert P, Dhayalan A, Murakami M, Zhang X, Tamas R, Jurkowska R, et al. Protein lysine methyltransferase G9a acts on nonhistone targets. Nat Chem Biol. 2008;4:344-6.
12. Huang J, Dorsey J, Chuikov S, Perez-Burgos L, Zhang X, Jenuwein T, et al. G9a and Glp methylate lysine 373 in the tumor suppressor p53. J Biol Chem. 2010;285:9636-41.

13. Lee JS, Kim Y, Kim IS, Kim B, Choi HJ, Lee JM, et al. Negative regulation of hypoxic responses via induced Reptin methylation. Mol Cell. 2010;39:71-85.

14. Kind J, Pagie L, Ortabozkoyun H, Boyle S, de Vries SS, Janssen $\mathrm{H}$, et al. Single-cell dynamics of genome-nuclear lamina interactions. Cell. 2013;153:178-92.

15. Zullo JM, Demarco IA, Pique-Regi R, Gaffney DJ, Epstein CB, Spooner CJ, et al. DNA sequence-dependent compartmentalization and silencing of chromatin at the nuclear lamina. Cell. 2012;149:1474-87.

16. Towbin BD, Gonzalez-Aguilera C, Sack R, Gaidatzis D, Kalck V, Meister P, et al. Step-wise methylation of histone H3K9 positions heterochromatin at the nuclear periphery. Cell. 2012;150:934-47.

17. Prokocimer M, Davidovich M, Nissim-Rafinia M, Wiesel-Motiuk N, Bar DZ, Barkan R, et al. Nuclear lamins: key regulators of nuclear structure and activities. J Cell Mol Med. 2009;13:105985.

18. Shinkai Y, Tachibana M. H3K9 methyltransferase G9a and the related molecule GLP. Genes Dev. 2011;25:781-8.

19. Esteve PO, Chin HG, Smallwood A, Feehery GR, Gangisetty O, Karpf AR, et al. Direct interaction between DNMT1 and G9a coordinates DNA and histone methylation during replication. Genes Dev. 2006;20:3089-103.

20. Ewen ME, Sluss HK, Sherr CJ, Matsushime H, Kato J, Livingston DM. Functional interactions of the retinoblastoma protein with mammalian D-type cyclins. Cell. 1993;73:487-97.

21. Wang C, Li Z, Lu Y, Du R, Katiyar S, Yang J, et al. Cyclin D1 repression of nuclear respiratory factor 1 integrates nuclear DNA synthesis and mitochondrial function. Proc Natl Acad Sci USA. 2006;103:11567-72.

22. Sakamaki T, Casimiro MC, Ju X, Quong AA, Katiyar S, Liu M, et al. Cyclin D1 determines mitochondrial function in vivo. Mol Cell Biol. 2006;26:5449-69.

23. Pestell RG. New roles of cyclin D1. Am J Pathol. 2013;183:3-9.

24. Hulit J, Wang C, Li Z, Albanese C, Rao M, Di Vizio D, et al. Cyclin D1 genetic heterozygosity regulates colonic epithelial cell differentiation and tumor number in ApcMin mice. Mol Cell Biol. 2004;24:7598-611.

25. Reutens AT, Fu M, Wang C, Albanese C, McPhaul MJ, Sun Z, et al. Cyclin D1 binds the androgen receptor and regulates hormone-dependent signaling in a p300/CBP-associated factor $(\mathrm{P} /$ CAF)-dependent manner. Mol Endocrinol. 2001;15:797-811.

26. Fu M, Wang C, Rao M, Wu X, Bouras T, Zhang X, et al. Cyclin D1 represses p300 transactivation through a cyclin-dependent kinase-independent mechanism. J Biol Chem. 2005;280:2972842.

27. Wang C, Pattabiraman N, Zhou JN, Fu M, Sakamaki T, Albanese $\mathrm{C}$, et al. Cyclin D1 repression of peroxisome proliferator-activated receptor gamma expression and transactivation. Mol Cell Biol. 2003;23:6159-73.

28. Zwijsen RM, Buckle RS, Hijmans EM, Loomans CJ, Bernards R. Ligand-independent recruitment of steroid receptor coactivators to estrogen receptor by cyclin D1. Genes Dev. 1998;12:3488-98.

29. Fu M, Rao M, Bouras T, Wang C, Wu K, Zhang X, et al. Cyclin D1 inhibits peroxisome proliferator-activated receptor gammamediated adipogenesis through histone deacetylase recruitment. J Biol Chem. 2005;280:16934-41.

30. Casimiro MC, Crosariol M, Loro E, Ertel A, Yu Z, Dampier W, et al. ChIP sequencing of cyclin D1 reveals a transcriptional role in chromosomal instability in mice. J Clin Invest. 2012;122:833-43.

31. Casimiro MC, Wang C, Li Z, Di Sante G, Willmart NE, Addya S, et al. Cyclin D1 determines estrogen signaling in the mammary gland in vivo. Mol Endocrinol. 2013;27:1415-28. 
32. Ju X, Casimiro MC, Gormley M, Meng H, Jiao X, Katiyar S, et al. Identification of a cyclin D1 network in prostate cancer that antagonizes epithelial-mesenchymal restraint. Cancer Res. 2014;74:508-19.

33. Mozzetta C, Pontis J, Fritsch L, Robin P, Portoso M, Proux C, et al. The histone H3 lysine 9 methyltransferases G9a and GLP regulate polycomb repressive complex 2-mediated gene silencing. Mol Cell. 2014;53:277-89.

34. Marampon F, Casimiro MC, Fu M, Powell MJ, Popov VM, Lindsay $\mathrm{J}$, et al. Nerve Growth factor regulation of cyclin D1 in PC12 cells through a p21RAS extracellular signal-regulated kinase pathway requires cooperative interactions between $\mathrm{Sp} 1$ and nuclear factor-kappaB. Mol Biol Cell. 2008;19:2566-78.

35. Lukaszewicz AI, Anderson DJ. Cyclin D1 promotes neurogenesis in the developing spinal cord in a cell cycle-independent manner. Proc Natl Acad Sci USA. 2011;108:11632-7.

36. Deimling SJ, Olsen JB, Tropepe V. The expanding role of the Ehmt2/G9a complex in neurodevelopment. Neurogenesis (Austin). 2017;4:e1316888

37. Walter J, Schermelleh L, Cremer M, Tashiro S, Cremer T. Chromosome order in HeLa cells changes during mitosis and early G1, but is stably maintained during subsequent interphase stages. J Cell Biol. 2003;160:685-97.

38. Strickfaden H, Zunhammer A, van Koningsbruggen S, Kohler D, Cremer T. 4D chromatin dynamics in cycling cells: Theodor Boveri's hypotheses revisited. Nucleus. 2010;1:284-97.

39. Amendola M, van Steensel B. Nuclear lamins are not required for lamina-associated domain organization in mouse embryonic stem cells. EMBO Rep. 2015;16:610-7.

40. Kind J, Pagie L, de Vries SS, Nahidiazar L, Dey SS, Bienko M, et al. Genome-wide maps of nuclear lamina interactions in single human cells. Cell. 2015;163:134-47.

41. Peric-Hupkes D, Meuleman W, Pagie L, Bruggeman SW, Solovei I, Brugman W, et al. Molecular maps of the reorganization of genome-nuclear lamina interactions during differentiation. Mol Cell. 2010;38:603-13.

42. Banaszynski LA, Chen LC, Maynard-Smith LA, Ooi AG, Wandless TJ. A rapid, reversible, and tunable method to regulate protein function in living cells using synthetic small molecules. Cell. 2006;126:995-1004.

43. Wozniak RJ, Klimecki WT, Lau SS, Feinstein Y, Futscher BW. 5Aza-2'-deoxycytidine-mediated reductions in G9A histone methyltransferase and histone H3 K9 di-methylation levels are linked to tumor suppressor gene reactivation. Oncogene. 2007;26:77-90.

44. Takawa M, Masuda K, Kunizaki M, Daigo Y, Takagi K, Iwai Y, et al. Validation of the histone methyltransferase EZH2 as a therapeutic target for various types of human cancer and as a prognostic marker. Cancer Sci. 2011;102:1298-305.

45. Cho HS, Kelly JD, Hayami S, Toyokawa G, Takawa M, Yoshimatsu M, et al. Enhanced expression of EHMT2 is involved in the proliferation of cancer cells through negative regulation of SIAH1. Neoplasia. 2011;13:676-84.

46. Ding J, Li T, Wang X, Zhao E, Choi JH, Yang L, et al. The histone H3 methyltransferase G9A epigenetically activates the serine-glycine synthesis pathway to sustain cancer cell survival and proliferation. Cell Metab. 2013;18:896-907.

47. Huang T, Zhang P, Li W, Zhao T, Zhang Z, Chen S, et al. G9A promotes tumor cell growth and invasion by silencing CASP1 in non-small-cell lung cancer cells. Cell Death Dis. 2017;8:e2726.

48. Chen WL, Sun HP, Li DD, Wang ZH, You QD, Guo XK. G9aan appealing antineoplastic target. Curr Cancer Drug Targets. 2017;17:555-68.

49. Wang TC, Cardiff RD, Zukerberg L, Lees E, Arnold A, Schmidt EV. Mammary hyperplasia and carcinoma in MMTV-cyclin D1 transgenic mice. Nature. 1994;369:669-71.
50. Casimiro MC, Di Sante G, Crosariol M, Loro E, Dampier W, Ertel A, et al. Kinase-independent role of cyclin D1 in chromosomal instability and mammary tumorigenesis. Oncotarget. 2015;6:8525-38.

51. Shambaugh GE 3rd, Lee RJ, Watanabe G, Erfurth F, Karnezis AN, Koch AE, et al. Reduced cyclin D1 expression in the cerebella of nutritionally deprived rats correlates with developmental delay and decreased cellular DNA synthesis. J Neuropathol Exp Neurol. 1996;55:1009-20.

52. Stahl M, Ge C, Shi S, Pestell RG, Stanley P. Notch1-induced transformation of RKE-1 cells requires up-regulation of cyclin D1. Cancer Res. 2006;66:7562-70.

53. Lindsay J, Jiao X, Sakamaki T, Casimiro MC, Shirley LA, Tran $\mathrm{TH}$, et al. ErbB2 induces Notch1 activity and function in breast cancer cells. Clin Transl Sci. 2008;1:107-15.

54. Bizen N, Inoue T, Shimizu T, Tabu K, Kagawa T, Taga T. A growth-promoting signaling component cyclin D1 in neural stem cells has antiastrogliogenic function to execute self-renewal. Stem Cells. 2014;32:1602-15.

55. Aggarwal P, Vaites LP, Kim JK, Mellert H, Gurung B, Nakagawa $\mathrm{H}$, et al. Nuclear cyclin D1/CDK4 kinase regulates CUL4 expression and triggers neoplastic growth via activation of the PRMT5 methyltransferase. Cancer Cell. 2010;18:329-40.

56. Li Z, Jiao X, Wang C, Shirley LA, Elsaleh H, Dahl O, et al. Alternative cyclin d1 splice forms differentially regulate the DNA damage response. Cancer Res. 2010;70:8802-11.

57. Takahashi A, Imai Y, Yamakoshi K, Kuninaka S, Ohtani N, Yoshimoto $\mathrm{S}$, et al. DNA damage signaling triggers degradation of histone methyltransferases through $\mathrm{APC} / \mathrm{C}(\mathrm{Cdh} 1)$ in senescent cells. Mol Cell. 2012;45:123-31.

58. Li Z, Wang C, Jiao X, Lu Y, Fu M, Quong AA, et al. Cyclin D1 regulates cellular migration through the inhibition of thrombospondin 1 and ROCK signaling. Mol Cell Biol. 2006;26:4240-56.

59. Fang TC, Schaefer U, Mecklenbrauker I, Stienen A, Dewell S, Chen MS, et al. Histone H3 lysine 9 di-methylation as an epigenetic signature of the interferon response. $J$ Exp Med. 2012;209:661-9.

60. Li Y, Schulz VP, Deng C, Li G, Shen Y, Tusi BK, et al. Setd1a and NURF mediate chromatin dynamics and gene regulation during erythroid lineage commitment and differentiation. Nucleic Acids Res. 2016;44:7173-88.

61. Czimmerer Z, Daniel B, Horvath A, Ruckerl D, Nagy G, Kiss M, et al. The transcription factor STAT6 mediates direct repression of inflammatory enhancers and limits activation of alternatively polarized macrophages. Immunity. 2018;48:75-90.e6.

62. Gong Z, Liu J, Xie X, Xu X, Wu P, Li H, et al. Identification of potential target genes of USP22 via ChIP-seq and RNA-seq analysis in HeLa cells. Genet Mol Biol. 2018;41:488-95.

63. Ramagopalan SV, Heger A, Berlanga AJ, Maugeri NJ, Lincoln MR, Burrell A, et al. A ChIP-seq defined genome-wide map of vitamin $\mathrm{D}$ receptor binding: associations with disease and evolution. Genome Res. 2010;20:1352-60.

64. Thomas PD, Campbell MJ, Kejariwal A, Mi H, Karlak B, Daverman R, et al. PANTHER: a library of protein families and subfamilies indexed by function. Genome Res. 2003;13:2129-41.

65. Mi H, Lazareva-Ulitsky B, Loo R, Kejariwal A, Vandergriff J, Rabkin S, et al. The PANTHER database of protein families, subfamilies, functions and pathways. Nucleic Acids Res. 2005;33 (Database issue):D284-8.

66. Huang da W, Sherman BT, Lempicki RA. Bioinformatics enrichment tools: paths toward the comprehensive functional analysis of large gene lists. Nucleic Acids Res. 2009;37:1-13.

67. Huang da W, Sherman BT, Lempicki RA. Systematic and integrative analysis of large gene lists using DAVID bioinformatics resources. Nat Protoc. 2009;4:44-57. 
68. Quinlan AR, Hall IM. BEDTools: a flexible suite of utilities for comparing genomic features. Bioinformatics. 2010;26:841-2.

69. Plaisier SB, Taschereau R, Wong JA, Graeber TG. Rank-rank hypergeometric overlap: identification of statistically significant overlap between gene-expression signatures. Nucleic Acids Res. 2010;38:e169.
70. Roopra A, Qazi R, Schoenike B, Daley TJ, Morrison JF. Localized domains of G9a-mediated histone methylation are required for silencing of neuronal genes. Mol Cell. 2004;14:727-38.

71. Peric-Hupkes D, van Steensel B. Role of the nuclear lamina in genome organization and gene expression. Cold Spring Harb Symp Quant Biol. 2010;75:517-24. 